\title{
Review \\ Morphology-Dependent Room-Temperature Ferromagnetism in Undoped ZnO Nanostructures
}

\author{
Hongtao Ren ${ }^{1, *(1)}$ and Gang Xiang $2, *$ (1) \\ 1 School of Materials Science and Engineering, Liaocheng University, Hunan Road No. 1, \\ Liaocheng 252000, China \\ 2 College of Physics, Sichuan University, Wangjiang Road No. 29, Chengdu 610064, China \\ * Correspondence: renhongtao@lcu.edu.cn (H.R.); gxiang@scu.edu.cn (G.X.)
}

check for

updates

Citation: Ren, H.; Xiang, G. Morphology-Dependent RoomTemperature Ferromagnetism in Undoped ZnO Nanostructures. Nanomaterials 2021, 11, 3199. https: / / doi.org/10.3390/nano11123199

Academic Editors: Julian Maria Gonzalez Estevez, Xiaoyan Li, Kai Liu and Yinghui Sun

Received: 10 October 2021 Accepted: 19 November 2021 Published: 25 November 2021

Publisher's Note: MDPI stays neutral with regard to jurisdictional claims in published maps and institutional affiliations.

Copyright: (C) 2021 by the authors. Licensee MDPI, Basel, Switzerland. This article is an open access article distributed under the terms and conditions of the Creative Commons Attribution (CC BY) license (https:/ / creativecommons.org/licenses/by/ $4.0 /)$.

\begin{abstract}
Since Dietl et al. predicted that Co-doped $\mathrm{ZnO}$ may show room-temperature ferromagnetism (RTFM) in 2000, researchers have focused on the investigation of ferromagnetic $\mathrm{ZnO}$ doped with various transition metals. However, after decades of exploration, it has been found that undoped $\mathrm{ZnO}$ nanostructures can also show RTFM, which in general is dependent on $\mathrm{ZnO}$ morphologies. Here, we will give an overall review on undoped $\mathrm{ZnO}$ nanomaterials with RTFM. The advanced strategies to achieve multidimensional (quasi- $0 \mathrm{D}, 1 \mathrm{D}, 2 \mathrm{D}$, and $3 \mathrm{D}$ ) ferromagnetic $\mathrm{ZnO}$ nanostructures and the mechanisms behind RTFM are systematically presented. We have successfully prepared ferromagnetic nanostructures, including thin films, horizontal arrays and vertical arrays. The existing challenges, including open questions about quantum-bound $\mathrm{ZnO}$ nanostructures, are then discussed.
\end{abstract}

Keywords: dimensional engineering; substrate engineering; thickness-dependence

\section{Introduction}

In recent years, due to their potential applications in spintronic devices, diluted magnetic semiconductors have attracted the attention of researchers [1]. Many research groups have attempted to look for compounds with room-temperature ferromagnetism (RTFM) since 2000, which can be obtained with doping transition metal elements into metal oxides including $\mathrm{ZnO}$ [2-6], $\mathrm{TiO}_{2}$ [7-10], $\mathrm{SnO}_{2}$ [11-16], $\mathrm{In}_{2} \mathrm{O}_{3}$ [17,18] and $\mathrm{HfO}_{2}[10,19-21]$. Since it was predicted based on the Zener model that Co-doped ZnO could exhibit RTFM [22], researchers have gradually focused on transition metal-doped $\mathrm{ZnO}$ systems. As an overview of the many publications on doped $\mathrm{ZnO}$ with RTFM, some review articles $[4,6,23-33]$ are presented in Table 1.

In fact, undoped $\mathrm{ZnO}$ can also exhibit ferromagnetic ordering. The spin state related with $\mathrm{Zn}$ vacancy $\left(\mathrm{V}_{\mathrm{Zn}}\right)$ was identified first by its electron spin resonance (ESR) spectrum in electron-irradiated $\mathrm{ZnO}$ single crystals [34]. It is worthwhile noting that recent experimental results have shown that nano-engineering can also induce ferromagnetic behavior in non-ferromagnetic bulk materials [35-37]. The magnetic ordering obtained by the minimum number of vacancies was not successfully detected at that time. Amazingly, it was found later that the miniature of the bulk materials in nanoscale, such as nanoparticles (NPs), could exhibit novel magnetic behaviors in undoped ZnO. In 2006, RTFM $\left(M_{s}\right.$, $\sim 0.0005 \mathrm{emu} / \mathrm{g}$ ) was observed in sol-gel ZnO NPs [38], which could be attributed to oxygen vacancies $\left(\mathrm{V}_{\mathrm{O}}\right)$. Subsequently, Banerjee et al. [39]. found that thermal annealing could induce RTFM in $\mathrm{ZnO}$ white powder, owing to the formation of $\mathrm{V}_{\mathrm{O}}$ clusters during the thermal treatment. Then, RTFM with a saturation magnetization up to $35.65 \mathrm{emu} / \mathrm{g}$ was also observed in undoped $\mathrm{ZnO}$ thin films (TFs) by pulsed laser deposition (PLD) and $\mathrm{V}_{\mathrm{Zn}}$ located at the surface or the interface of the samples could be the source of RTFM [40]. More importantly, various $\mathrm{ZnO}$ nanostructures with RTFM were obtained by various approaches, such as ionic layer epitaxy [41], polymer-assisted deposition (PAD) [42-44], electrochemical deposition method [45], sol-gel [36,46,47], ball milling (BM) [48-50], and PLD [51], etc. 
Here, we will give an overview of the timeline of undoped $\mathrm{ZnO}$ nanostructures with RTFM (Figure 1).

Table 1. Summary of research on ferromagnetic (FM) zinc oxide. RTFM (room-temperature ferromagnetism).

\begin{tabular}{|c|c|c|}
\hline Topic & Year & References \\
\hline RTFM of TM-doped ZnO films & 2005 & [23] \\
\hline RTFM of TM-doped ZnO films & 2008 & {$[4]$} \\
\hline Theoretical and experimental studies of $\mathrm{ZnO}$-based DMS & 2010 & [24] \\
\hline RTFM of capped ZnO nanoparticles & 2011 & [25] \\
\hline Defect-induced magnetism in undoped $\mathrm{ZnO}$ & 2013 & [26] \\
\hline RTFM in $\mathrm{ZnO}$ nanomaterials & 2013 & [27] \\
\hline ZnO-from dilute magnetic doping to spin transport & 2014 & [28] \\
\hline Defect-driven RTFM in undoped $\mathrm{ZnO}$ & 2015 & [6] \\
\hline Surface and/or interface RTFM of undoped $\mathrm{ZnO}$ nanoparticles & 2015 & [29] \\
\hline RTFM in ZnO: TM & 2016 & [30] \\
\hline Vacancy defect-induced RTFM in undoped $\mathrm{ZnO}$ nanostructures & 2017 & [31] \\
\hline ZnO-based dilute magnetic semiconductor & 2020 & [32] \\
\hline
\end{tabular}

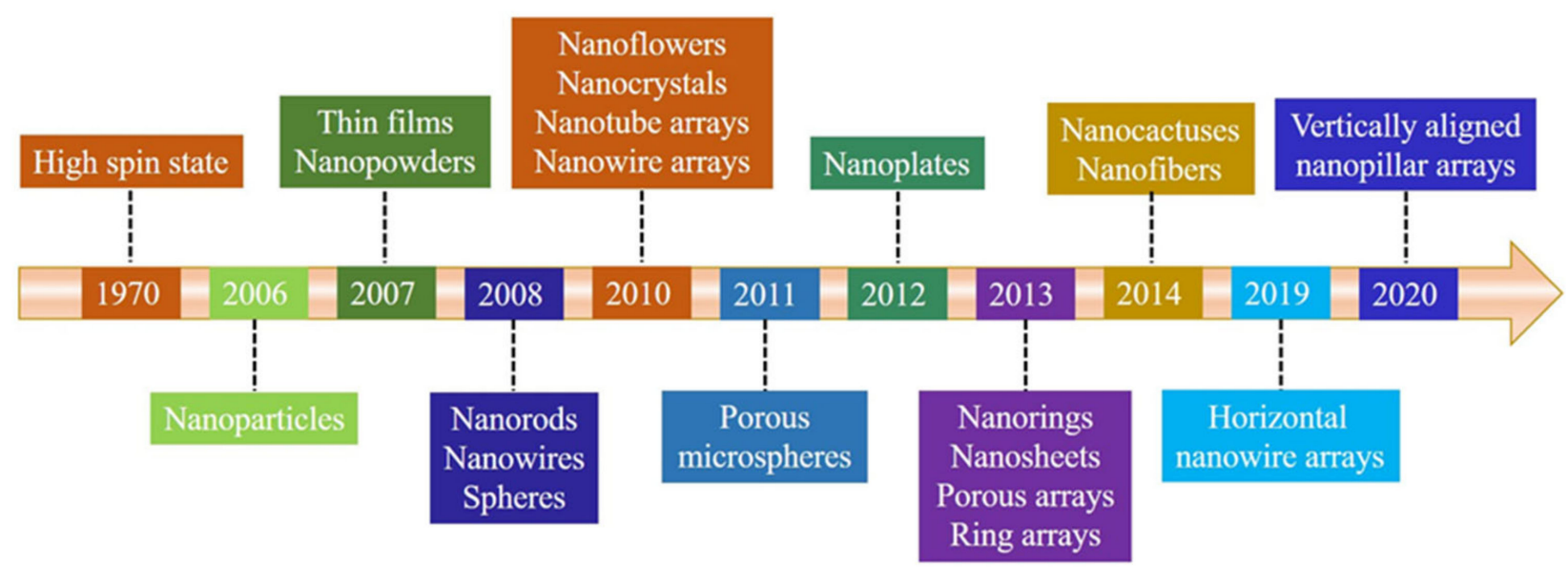

Figure 1. Timeline showing key developments of $\mathrm{ZnO}$ nanostructures with RTFM.

\section{Dimension Design}

$\mathrm{ZnO}$ nanostructures can be divided into the following categories according to dimensions, such as: quasi-0D materials (quantum dots (QDs), and nanoparticles (NPs), 1D materials (nanorods (NRs), nanowires (NWs), nanostructured arrays, capped nanowires/nanotubes arrays, and other nanostructures), 2D materials (nanosheets, nanoplates, and thin films (TFs)), and 3D materials (single crystals, and porous microspheres).

\subsection{Zero- and Quasi Zero-Dimensional Materials}

Qusai-0D materials, such as Quantum dots (QDs), are crystalline particles with sizes less than $100 \mathrm{~nm}$. ZnO QDs with RTFM (Figure 2) are commonly deposited by sol-gel (SOL) [36,47,52-54], solid-state reactions (SSR) [38], ball milling (BM) [49,55-61] pulsed laser deposition (PLD) [51], and coprecipitation (COP) [62,63] and so on. Previous studies have shown that RTFM of QDs can be controlled by synthetic temperature [52], milling time, annealing temperature or atmosphere [53,54], Zn source and capping [36,47]. As another kind of quasi zero dimensional material, nanoparticles (NPs) are about hundreds of nanometers in size. ZnO NPs with RTFM have been synthesized by BM [49,59], microwave plasma assisted spray (MPAS) [64], the miceller method (MIC) [39], COP [62] and the surfactant-free wet chemical method (SWCM) [65] (Figure 2). It has also been found that RTFM can be controlled by annealing parameters [39,59,62,65], particle size [64] and milling time [49]. The size-dependent RTFM in ZnO QDs/NPs (Figure 3) can be observed [52]. 
$M_{s}$ is increased gradually by decreasing the diameters of ZnO NPs, and then RTFM will transform into paramagnetism (PM) or diamagnetism (DM).

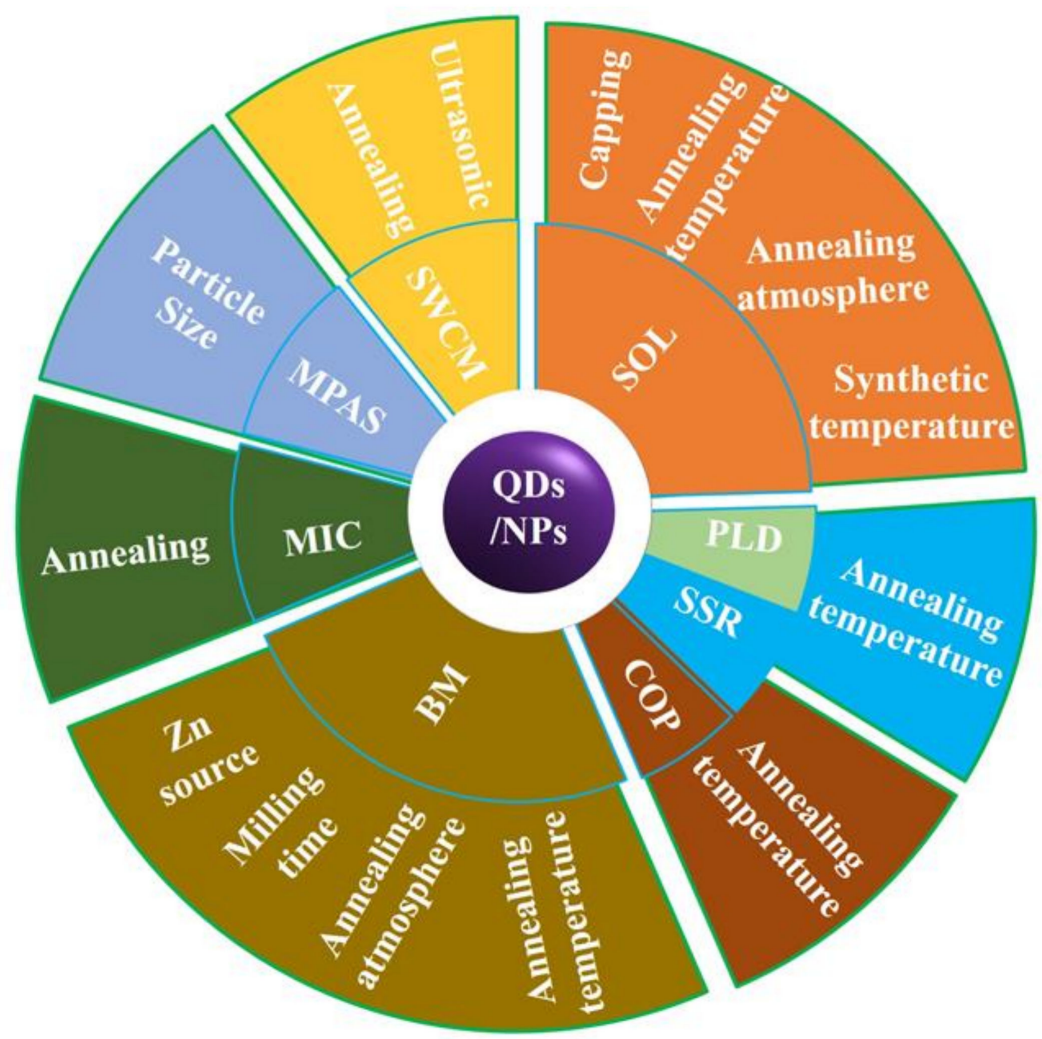

Figure 2. Overview of currently available preparation strategies for fabricating $\mathrm{ZnO}$ QDs/NPs with RTFM. Sol-gel (SOL); Pulsed laser deposition (PLD); Solid-state reactions (SSR); Coprecipitation (COP); Ball milling (BM); Miceller method (MIC); Microwave plasma assisted spray (MPAS); Surfactant-free wet chemical method (SWCM).

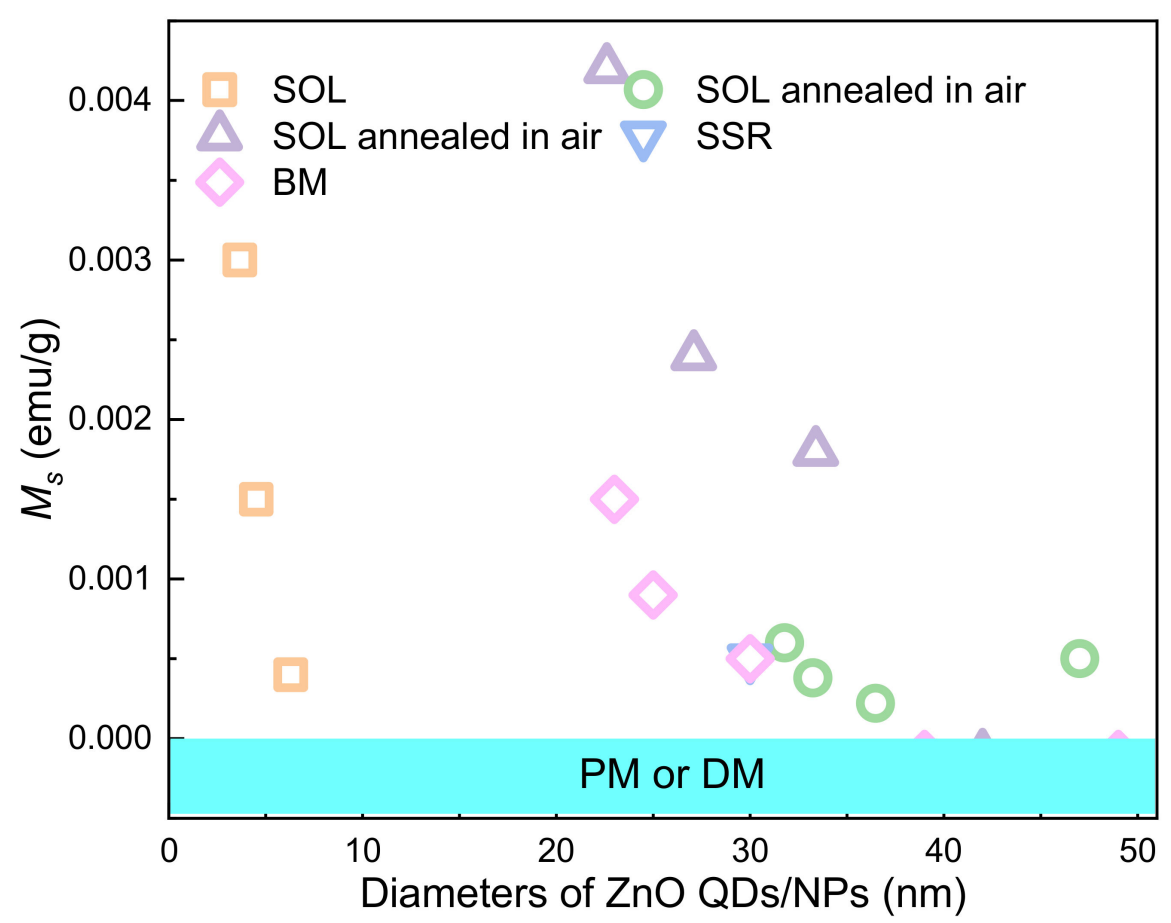

Figure 3. The size-dependent RTFM in ZnO QDs/NPs. 


\subsection{One-Dimensional Materials}

\subsubsection{Nanowires/Nanorods}

RTFM has been found in ZnO NWs [66] prepared by electro-deposition (ED). Due to the incomplete oxidation of zinc NWs, zinc clusters are formed in $\mathrm{ZnO} N W s$, which induce room temperature ferromagnetism. Subsequently, $\mathrm{ZnO}$ NRs exhibiting RTFM have been obtained by hydrothermal method (HYT) [67] with $\mathrm{Zn}(\mathrm{Ac})_{2} \cdot 2 \mathrm{H}_{2} \mathrm{O}$ and $\mathrm{NaOH}$ (Figure 4A). When the diameters of the NRs decreases, the $M_{s}$ of the as-grown sample increases. $Z \mathrm{n}_{\mathrm{i}}$ at the surface of ZnO NRs may be one of the reasons for RTFM.

In addition, $\mathrm{V}_{\mathrm{Zn}}$ can also be produced in $\mathrm{ZnO}$ NRs with RFTM (Figure 4B), which were synthesized by COP [68]. The as-prepared NWs [69] (Figure 4C) show an obvious RTFM $\left(M_{s}, \sim 0.007 \mathrm{emu} / \mathrm{g}\right)$. However, highly crystalline ZnO NWs [69] (Figure 4) prepared by the pulsed laser vaporization (PLV) process show no RTFM. X-ray fine structure spectroscopy study confirms that $\mathrm{V}_{\mathrm{Zn}}$ can cause RTFM in ZnO NRs.

Furthermore, $\mathrm{ZnO}$ NRs have been obtained in aqueous conditions [70]. As-prepared NRs show RTFM behavior. Strangely, when the size of the NRs decrease, the magnetization of $\mathrm{ZnO}$ NRs increases. Singly charged oxygen vacancies $\left(\mathrm{V}_{\mathrm{O}^{+}}\right)$localized on the sample is the origin of RTFM. Single-crystalline ZnO NWs with RTFM $\left(M_{s}, \sim 0.001 \mathrm{emu} / \mathrm{g}\right)$ (Figure 4D,E) have been obtained by the vapor transport method (VTM) [71]. RTFM related with $V_{O}$ can be modulated by selecting different catalysts and changing the growth temperature. Jana et al. [72] has reported $\mathrm{ZnO} N R s\left(M_{s}, \sim 0.059 \mathrm{emu} / \mathrm{g}\right)$ using hydrolysis of zinc acetate. Moreover, polycrystalline ZnO NRs with RTFM have also been prepared by a wet chemical method (WCM) [73]. RTFM in ZnO NRs (Figure 4) is attributed to $\mathrm{V}_{\mathrm{O}^{+}}$.

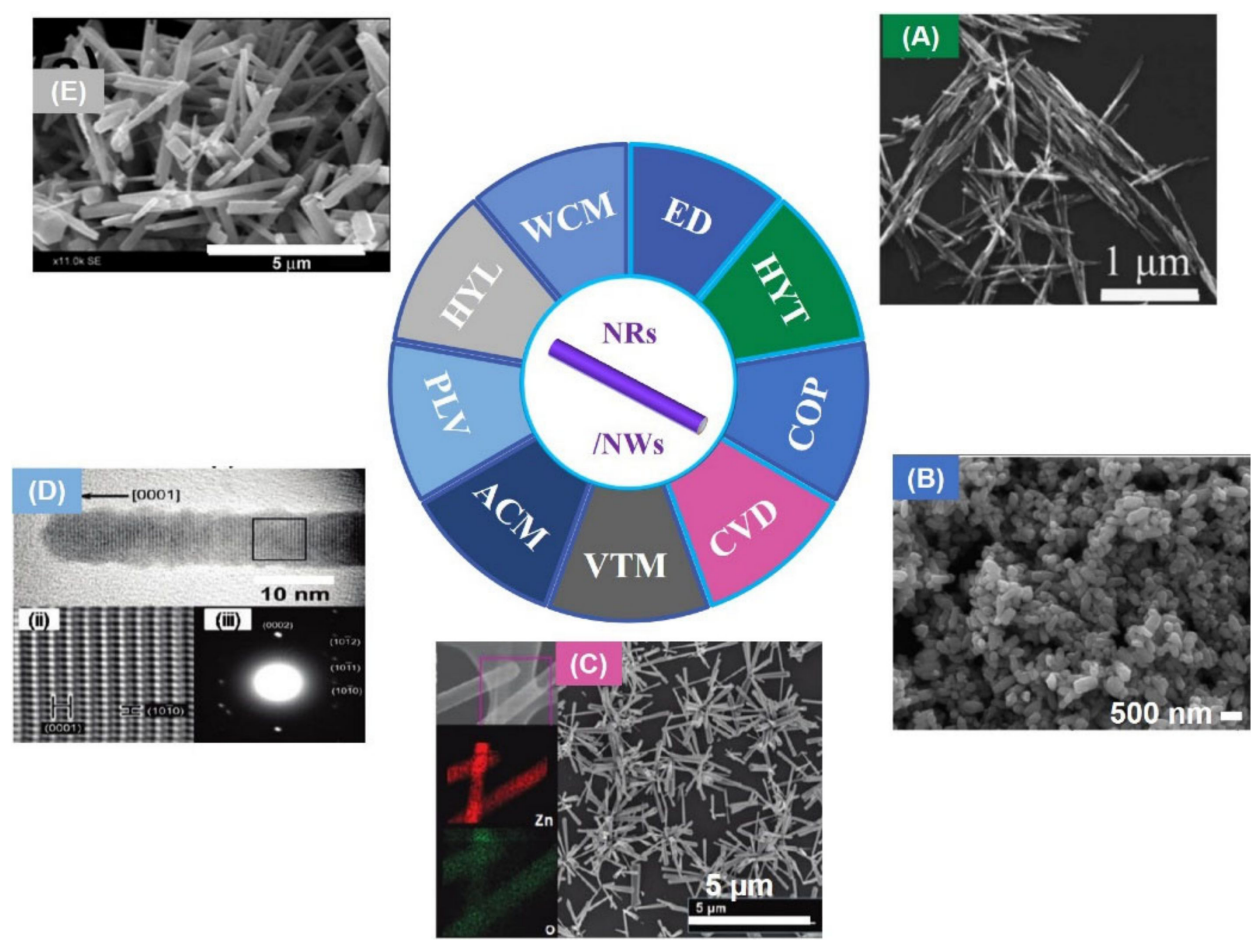

Figure 4. ZnO NRs/NWs. (A) ZnO NRs obtained by hydrothermal method (HYT) (Reproduced with permission from [67]. Copyright 2008, American Institute of Physics). (B) ZnO NRs prepared by coprecipitation method (COP) (Reproduced with permission from [68]. Copyright 2009, Elsevier). (C) SEM images of ZnO NWs (Reproduced with permission from [69]. Copyright 2010, American Chemical Society). (D) HRTEM image of ZnO NRs (Reproduced with permission from [69]. Copyright 2010, American Chemical Society). (E) ZnO NRs synthesised by wet chemical method (WCM) (Reproduced with permission from [72]. Copyright 2018, Elsevier). Electro-deposition (ED); Chemical vapor deposition (CVD); Pulsed laser vaporization (PLV); Aqueous chemical method (ACM); Hydrolysis (HYL). 


\subsubsection{Nanostructure Arrays}

$\mathrm{ZnO}$ nanostructure arrays (Figure 5) have been fabricated by various approaches, such as HYT [74], colloidal template method (CTM) [75], chemical vapor deposition (CVD) [76], chemical bath deposition (CBD) [76,77], and polymer-assisted deposition (PAD) [42-44]. $\mathrm{ZnO}$ NWs are usually synthesized by a seed method. Firstly, ZnO TFs are prepared by magnetron sputtering and used as seed layer, then $\mathrm{ZnO}$ NRs arrays are obtained by HYT [74]. The defect states are controlled by annealing in $\mathrm{O}_{2}$ and $\mathrm{H}_{2}$ atmosphere at $500{ }^{\circ} \mathrm{C}$, respectively. It has been found that $\mathrm{V}_{\mathrm{O}}$ is closely related to RTFM by PL spectrum and vibrating sample magnetometer (VSM). Furthermore, vertically oriented NRs arrays (VNRA) and randomly oriented NRs arrays (RNRA) have been synthesized by CVD and CBD [76]. These results show that RTFM is originated from the $\mathrm{V}_{\mathrm{O}^{+}}$.

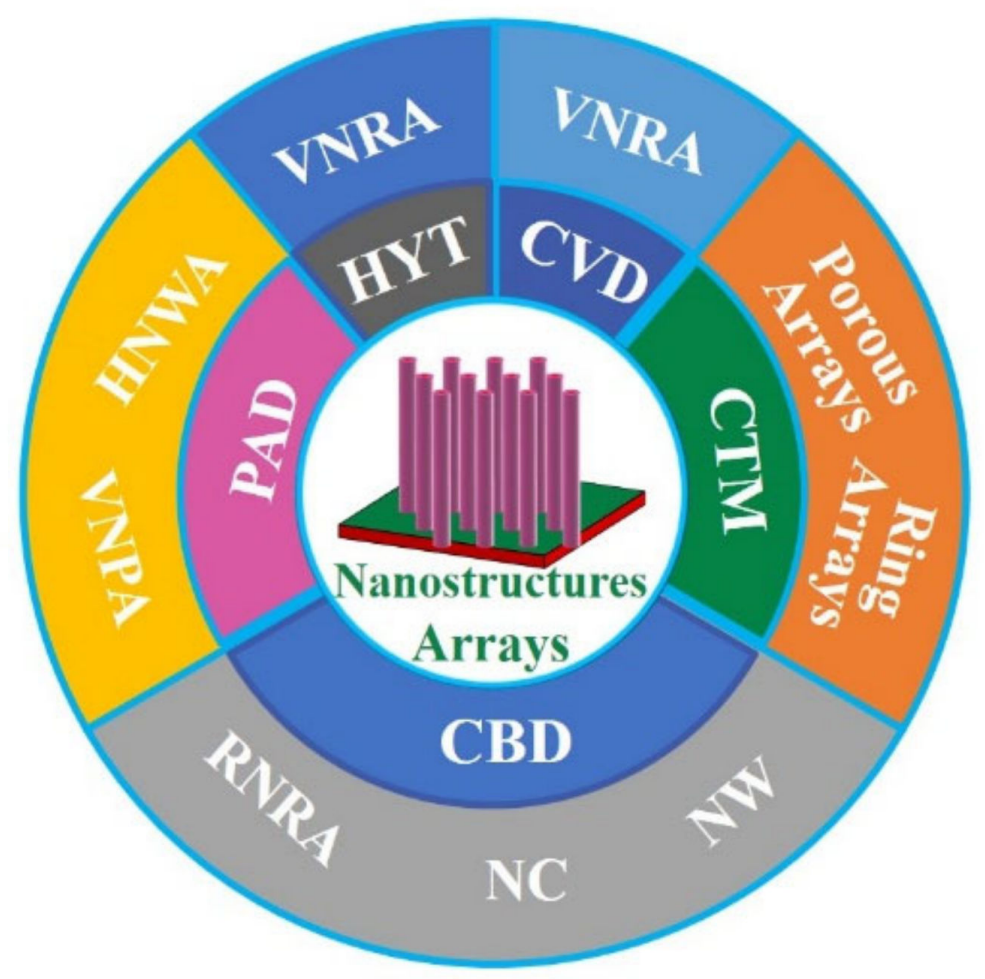

Figure 5. $\mathrm{ZnO}$ nanostructure arrays.

Interestingly, $\mathrm{ZnO}$ porous arrays $\left(M_{s}, \sim 5.7 \mathrm{emu} / \mathrm{g}\right)$ and ring arrays with $\operatorname{RTFM}\left(M_{s}\right.$, $\sim 0.25 \mathrm{emu} / \mathrm{g}$ ) have been fabricated by CTM [75] (Figure 5). When the grain size decreases to $\sim 3 \mathrm{~nm}$, the $M_{s}$ can increase to $\sim 5.7 \mathrm{emu} / \mathrm{g}$. The results show that grain size and $\mathrm{V}_{\mathrm{O}}$ concentration can affect the RTFM. The presence of the defects in ZnO nanocactuses $\left(M_{s}\right.$, $\left.\sim 3.0 \mathrm{emu} / \mathrm{cm}^{3}\right)$ than in the ZnO NWs $\left(M_{s}, \sim 2.3 \mathrm{emu} / \mathrm{cm}^{3}\right)$ was observed [77] in Figure 5 . The low temperature method can generate more defects, and then induce the higher $M_{s}$ in nanocactuses. ZnO HNWA [43] and VNPA [44] have also been obtained by PAD in our lab. Our results show that more $\mathrm{V}_{\mathrm{Zn}}$ can potentiate RTFM [43,44]. Thiol-capped $\mathrm{ZnO}$ NWs/NTs arrays can present RTFM [78]. The M-H loops of the thiol-capped samples reveal the height-dependent and morphology-dependent RTFM (Figure 6). Combing magnetic measurements and calculations show that the origin of ferromagnetism is mainly attributed to spin-polarized $3 p$ electrons in $S$ sites and, therefore, has a strong correlation with $\mathrm{Zn}-\mathrm{S}$ bond anisotropy.

In the nanowire system, the change of diameter has no obvious effect on RTFM (Figure 7). However, the height-dependent RTFM has been observed in capped $\mathrm{ZnO}$ NWs (Figure 6A). 

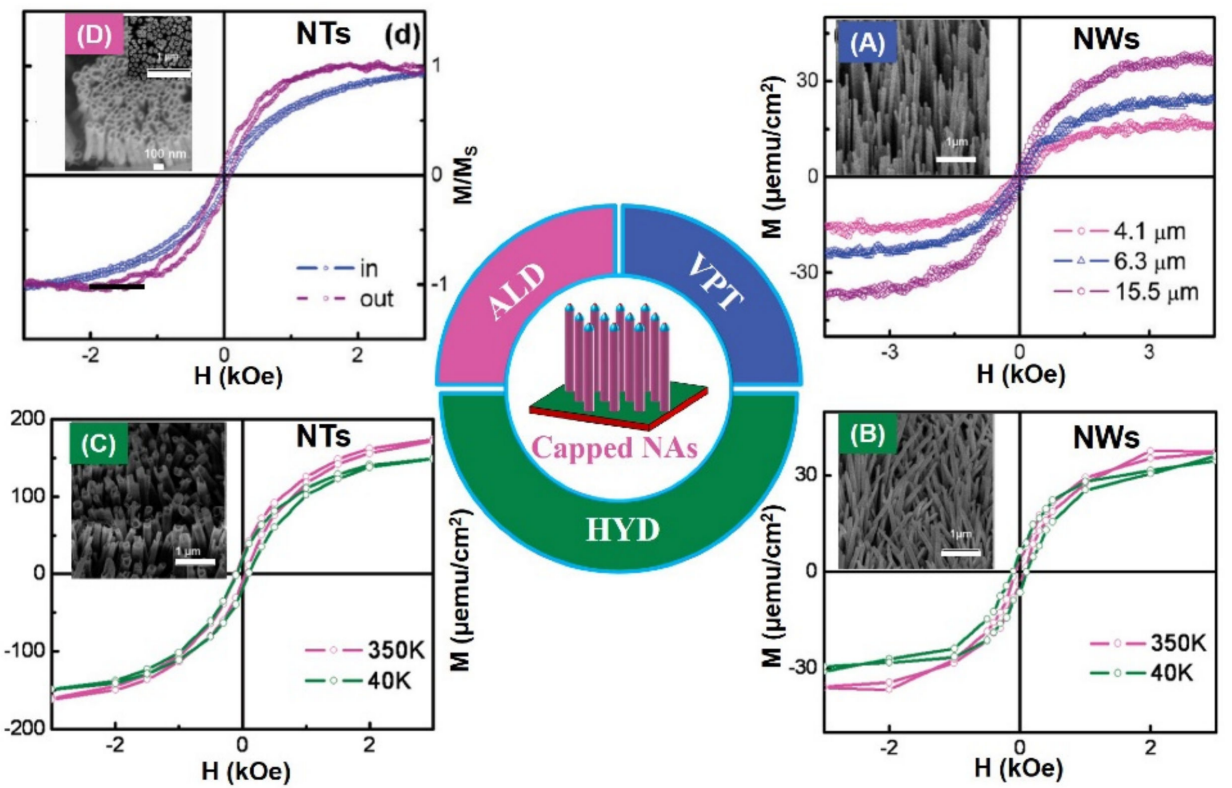

Figure 6. RTFM of ZnO nanowire (NWs) / nanotube arrays (NTs) is modulated by capping with thiol. (A) $\mathrm{M}-\mathrm{H}$ curves for $\mathrm{ZnO}$ NWs of different heights. (B) $\mathrm{M}-\mathrm{H}$ curves for $\mathrm{ZnO} \mathrm{NW}$ arrays of diameters $\sim 150 \mathrm{~nm}$. (C) M-H curves for ZnO NT arrays. (D) NT arrays (Reproduced with permission from [78]. Copyright 2009, Elsevier).

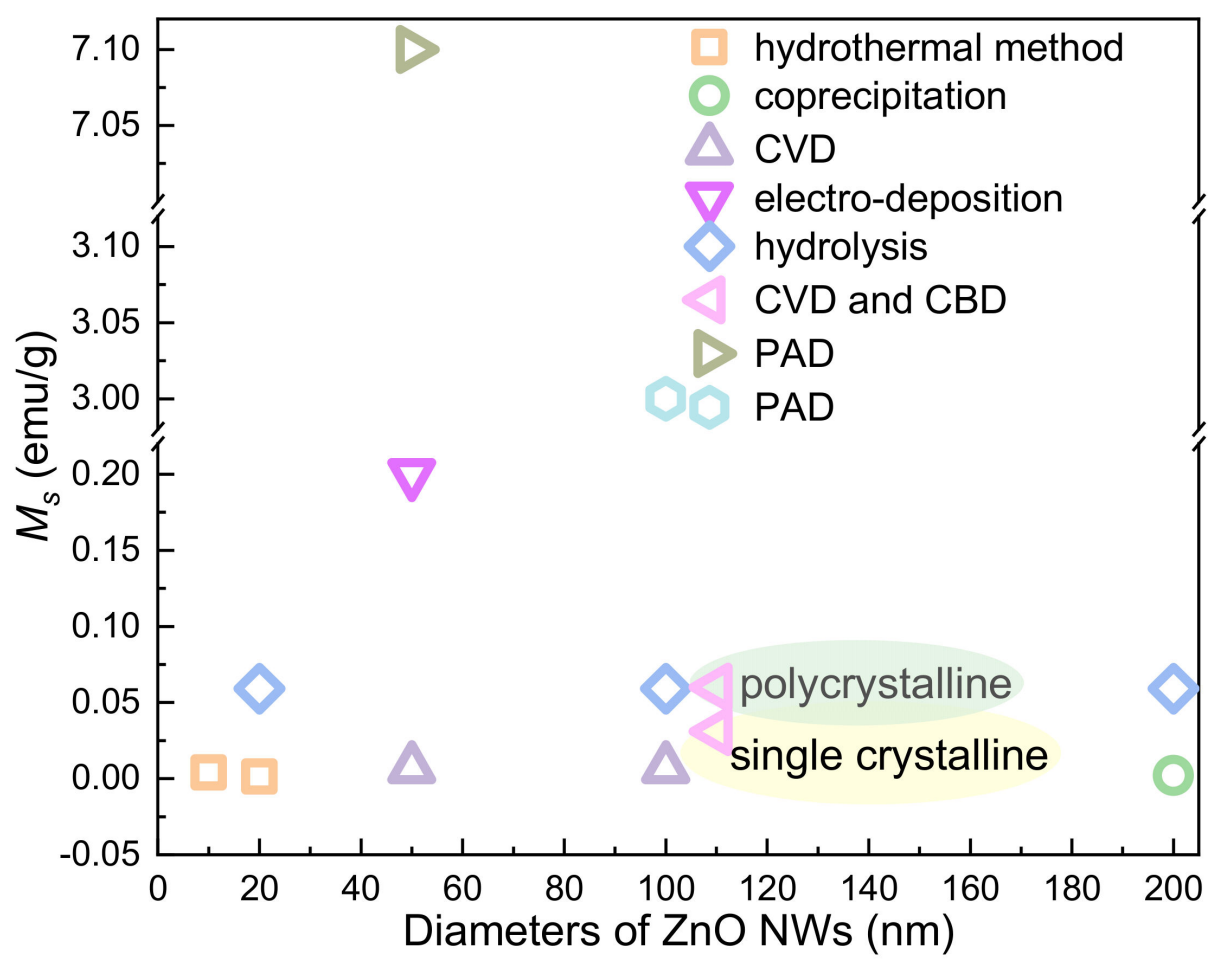

Figure 7. The size-dependent RTFM in ZnO NWs.

\subsubsection{Other Nanostructures}

$\mathrm{ZnO}$ nanoflowers with RTFM $\left(M_{s}, \sim 0.069 \mathrm{emu} / \mathrm{g}\right)$ have been obtained by HYT [79]. TEM images show that this flower sample is composed of closely packed NRs. XPS indicates that isolated vacancy clusters is closely related to the RTFM. In addition, microdiscs and porous nanoassembly of $\mathrm{ZnO}$ have been synthesized by soft-chemical approaches [80]. Furthermore, various types of $\mathrm{ZnO}$ nanostructures have been obtained by a microwave as- 
sisted HYT [81]. Spectrum measurements show that the defects may mediate RTFM [80,81]. The morphology-dependent RTFM is shown in Figure 8. ZnO HNWA has the highest $M_{s}$ is $\sim 7.1 \mathrm{emu} / \mathrm{g}$.

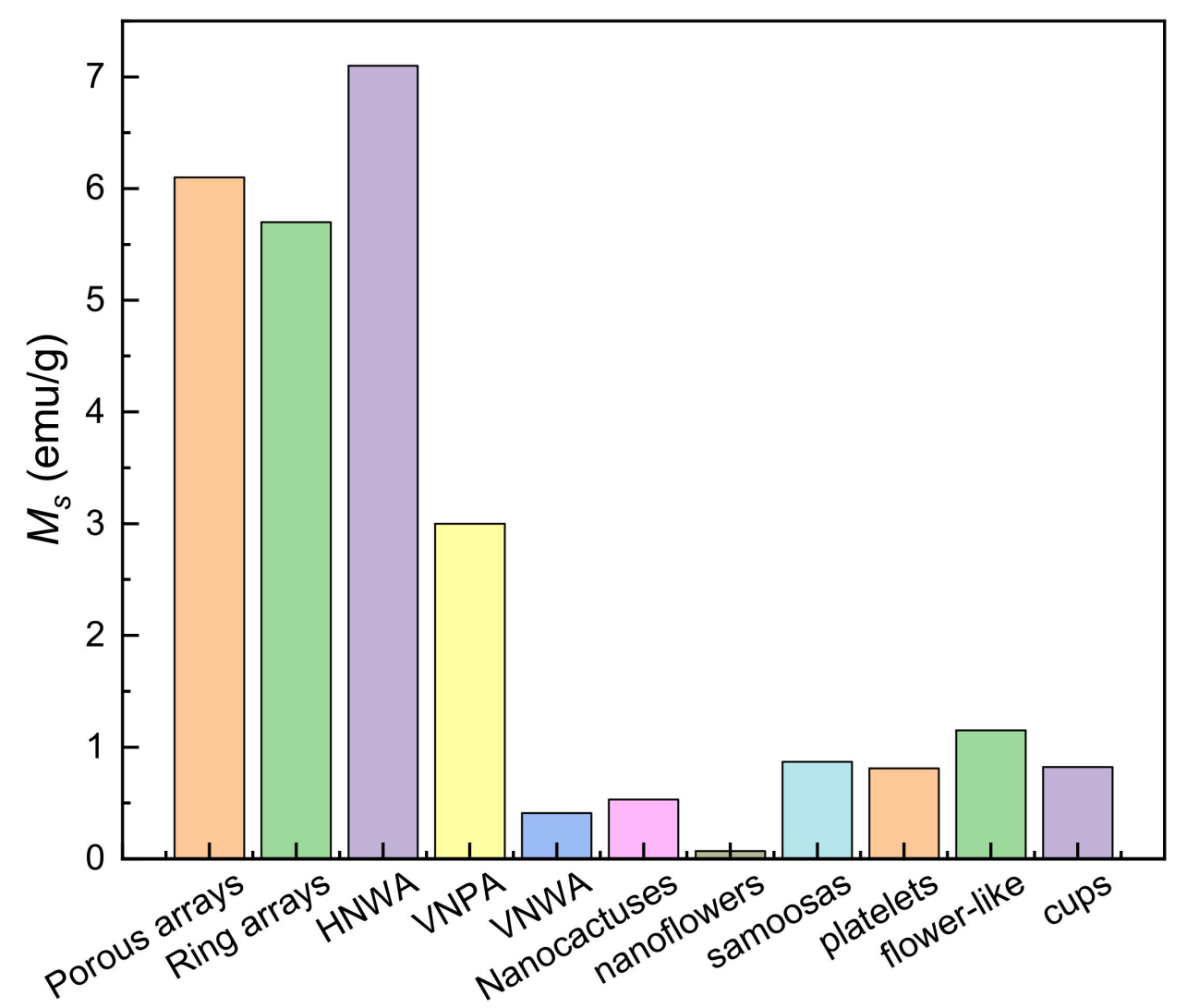

Figure 8. Saturation magnetizations $\left(M_{S}\right)$ of various $\mathrm{ZnO}$ nanostructures. Data from refs. $[43,44,75,77,79,81]$.

\subsection{Two-Dimensional Materials}

\subsubsection{Nanosheets/Nanoplates}

Two-dimensional (2D) nanosheets/nanoplates have been synthesized by HYT [45,82,83] and ionic layer epitaxy (ILE) [41] in Figure 9. The average thickness of ZnO Nanoplates is estimated to be $\sim 20 \mathrm{~nm}$ by the SEM images and XRD peak. Interestingly, it is only when the thickness is reduced to $5-8 \mathrm{~nm}$, the samples exhibit RTFM. Interestingly, first principles calculation results show that when the thickness of the NSs decreases to a certain range, the magnetic moment will be generated; however, when the size of the NWs decreases along the a-axis and b-axis, the magnetic moment will not be generated. The distorted bands may be responsible for the RTFM in $\mathrm{ZnO}$ nanoplates.

$\mathrm{ZnO}$ single-crystalline nanosheets with RTFM have been obtained [45]. TEM images present that $\mathrm{ZnO}$ sheets and dodecyl sulfate bilayers compose the lamellar structure. The results show the cluster of spin-polarized defects induce RTFM in single-crystalline $\mathrm{ZnO}$ nanosheets.

Two-dimensional $\mathrm{ZnO}$ nanosheets with high $\mathrm{V}_{\mathrm{Zn}}$ concentration have been grown by ILE [41] (Figure 9E,G). The nanosheets annealed in $\mathrm{Ar}$ at $400{ }^{\circ} \mathrm{C}$ for $1 \mathrm{~h}$ show $M_{S}$ of $50.9 \mathrm{emu} / \mathrm{g}$ in Figure 9G. Significantly, DFT calculations and experimental results suggest that $\mathrm{V}_{\mathrm{Zn}}$ could be associated with the RTFM.

By contrast with 2D materials, $\mathrm{ZnO}$ nanosheets do not show obvious thickness dependence. However, $\mathrm{ZnO}$ nanosheets with saturation magnetization up to $50.9 \mathrm{emu} / \mathrm{g}$ have been obtained recently by ILE (Figure 10). 

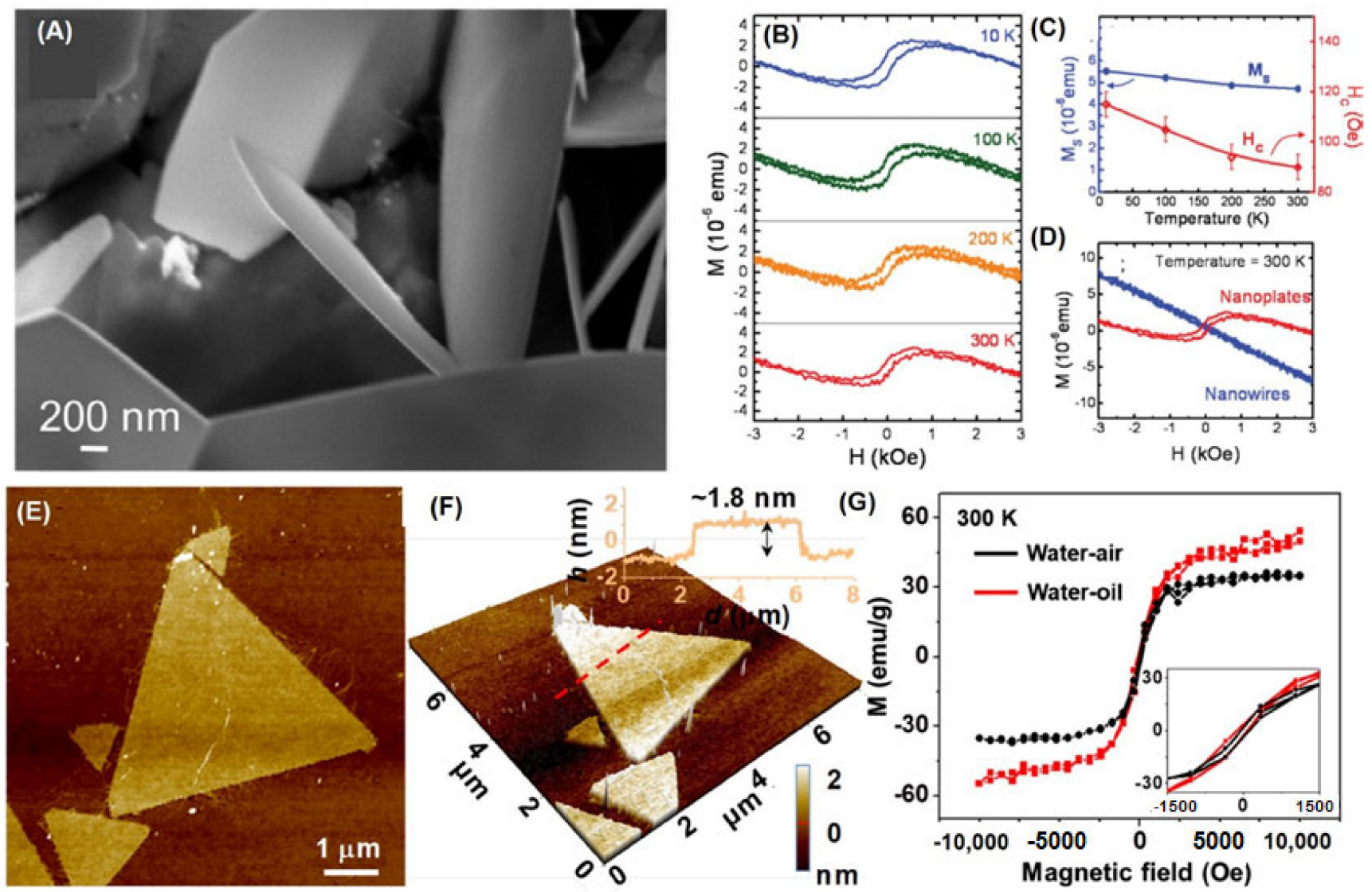

Figure 9. (A) $\mathrm{ZnO}$ nanoplates synthesized by HYT. (B) $\mathrm{M}-\mathrm{H}$ curves for $\mathrm{ZnO}$ nanoplates. (C) The corresponding $M_{S}$ and coercivities $H_{c}$ are plotted in (A). (D) M-H curves for $\mathrm{ZnO}$ nanowires and nanoplates (Reproduced with permission from [82]. Copyright 2012, American Chemical Society). (E,F) AFM images of two-dimensional (2D) ZnO nanosheets by ILE. (G) M-H curves for 2D ZnO nanosheets (Reproduced with permission from [41]. Copyright 2019, American Chemical Society).

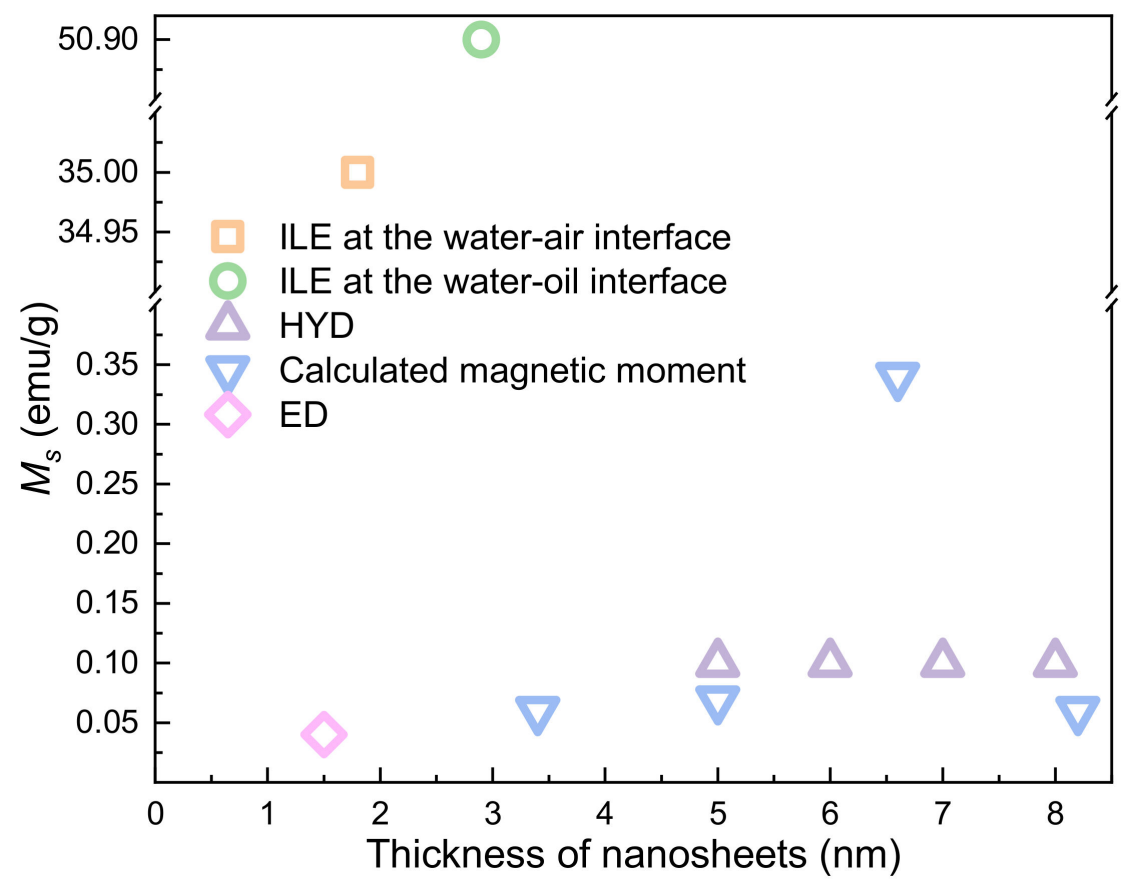

Figure 10. The thickness-dependent RTFM in $\mathrm{ZnO}$ nanosheets. 


\subsubsection{Thin Films}

In 2007, RTFM has been first observed in undoped ZnO TFs by PLD [40]. The results suggest that $\mathrm{V}_{Z n}$ can generate $R T F M$, where the ferromagnetism is related to the thickness of $\mathrm{ZnO}$ TFs. Soon after, calculations [84] not only showed that undoped $\mathrm{ZnO}$ TFs and NWs can be ferromagnetic but also indicated that $\mathrm{V}_{\mathrm{Zn}}$ is responsible for RTFM in lowdimensional magnetic $\mathrm{ZnO}$ nanostructures. Similar to other nanostructures $[38,40,67,80,81]$, $\mathrm{V}_{\mathrm{Zn}}$ prefers to reside on $\mathrm{ZnO}$ NWs, resulting in stronger RTFM.

The thickness-dependent ferromagnetism in ZnO TFs has been investigated by Kapilashrami et al. [85]. With increasing the film thickness, the ferromagnetism first increases; when the film thickness exceeds $480 \mathrm{~nm}\left(M_{s}, \sim 0.62 \mathrm{emu} / \mathrm{g}\right)$, the ferromagnetism then decreases; with increasing of film thickness, the ferromagnetism will transform into paramagnetism (PM) or even diamagnetism (DM). The defect is mainly responsible for the observed RTFM.

Grain boundaries can also mediate RTFM. ZnO TFs were also obtained by liquid ceramics method [86]. The HRTEM images show that $\mathrm{ZnO}$ grains is surrounded by the amorphous area. Furthermore, RTFM origins from the amorphous regions related the defects. By decreasing the grain size, the magnetic volume fractions will increase [87]. Tietze et al. [87]. built a magnetic shell model related to the grain boundaries, which clarified the origin of RTFM in ZnO TFs.

In the ZnO TFs system, $V_{Z n}[40,84,88-90]$ can also induce the RTFM. The existence of $\mathrm{V}_{\mathrm{Zn}}$ is often confirmed by photoluminescence and positron annihilation spectrum. Xing et al. [88] has found that the sol-gel derived samples contain more $V_{Z n}$, compared with the MBE-ZnO TFs, which shows much stronger RTFM. Similarly, $\mathrm{V}_{\mathrm{Zn}}$ is also the origin of RTFM in polycrystalline ZnO TFs prepared by PAD in our lab [89,90].

Additionally, undoped ZnO TFs [91,92] have been fabricated with CVD [93]. Interestingly, a nanosized structure can induce RTFM in ZnO TFs. Similar to ZnO NRs [71,76], $\mathrm{V}_{\mathrm{O}}$ can generate RTFM in undoped ZnO TFs obtained by PED [94] and undoped ZnO NPs prepared by an electrospinning method [95]. Moreover, Zhang et al. [96] indicated that RFTM in pure $Z n O$ TFs should be related to $Z n_{i}$. The shallow donor caused by $Z n_{i}$ defects might modify the electronic structure of ZnO TFs, leading to the RTFM.

The thickness dependence of RTFM has been observed in films prepared by different experimental methods (Figure 11). The RTFM of ZnO TFs is affected by the defects on the surface of the sample or at the interface between the sample and the substrate.

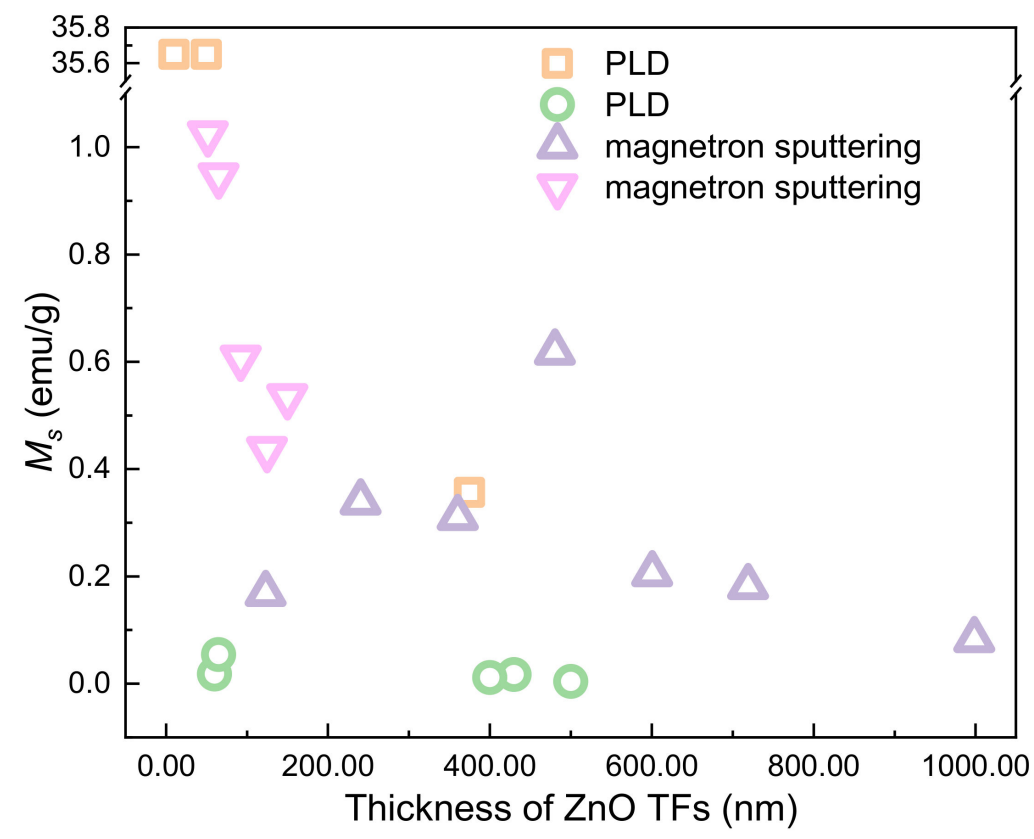

Figure 11. The thickness-dependent RTFM in ZnO TFs. 


\subsection{Three-Dimensional Materials}

In 1970, Galland et al. [34] irradiated ZnO single crystals with 3MeV electrons. ESR spectra showed that $V_{Z n}$ can generate the high spin state. Furthermore, the intrinsic defect just like $\mathrm{Zn}_{\mathrm{i}}$ and $\mathrm{V}_{\mathrm{O}}$ may give rise to the RTFM in single crystalline $\mathrm{ZnO}$ [97].

Interestingly, the metal-insulator transition has been found in the $\mathrm{ZnO}$ supercells adsorbed with hydrogen atoms by first-principles calculations [98]. This phase transition can affect the magnetic transformation. Experimentally, $\mathrm{ZnO}$ single crystals have been obtained by HTY [99]. The hydrogen penetration depth is confirmed at $20 \mathrm{~nm}$ by stopping and range of ions in matter (SRIM) simulation. SQUID measurements indicate that the $M_{S}$ increases with the treatment time and the concentration of hydrogen. Subsequently, hydrogen atoms may trigger the RTFM in ZnO single crystals in Khalid et al. [100]. The $M_{s}$ is up to $\sim 4 \mathrm{emu} / \mathrm{g}$. Strangely, the vacancies defects and the interstitial $\mathrm{Zn}$ atoms cannot induce the RTFM in $\mathrm{ZnO}$ monocrystal [101].

HYT [102] has been developed to grow $\mathrm{Zn}_{5}(\mathrm{OH})_{8} \mathrm{Ac}_{2} \cdot 2 \mathrm{H}_{2} \mathrm{O}$ microspheres. In fact, the microspheres are grown from the nanosheets, which are curved and connected to each other. $\mathrm{ZnO}$ porous microspheres [103] have been obtained from $\mathrm{Zn}_{5}(\mathrm{OH})_{8} \mathrm{Ac}_{2} \cdot 2 \mathrm{H}_{2} \mathrm{O}$ microspheres annealing at $500{ }^{\circ} \mathrm{C}$. The RTFM in pure $\mathrm{ZnO}$ microspheres origins from $\mathrm{V}_{\mathrm{Zn}}$ and shallows donors.

\section{Ferromagnetism of Undoped ZnO Nanostructures}

\subsection{Influence of Precursor Selection on Room-Temperature Ferromagnetism (RTFM)}

The preparation of materials has always been optimized by selecting more suitable precursors. In $2019, \mathrm{Zn}\left(\mathrm{NO}_{3}\right)_{2} \cdot 6 \mathrm{H}_{2} \mathrm{O}$ and $\mathrm{ZnCl}_{2}$ were selected as zinc sources to prepare $\mathrm{ZnO}$ NPs [104]. The difference of $M_{s}$ was nearly four times, which may have been due to $\mathrm{V}_{\mathrm{O}}$ in the samples produced by selecting different precursors.

\subsection{Substrate Effects on Ferromagnetism}

Substrates have played an important role in material synthesis [4,93,94,105-108]. ZnO TFs have been grown on single-crystalline substrates by MOCVD [93]. M-H curves show that $\mathrm{ZnO}$ TFs on sapphire substrate are non-ferromagnetic (Figure 12A,B). However, the structural defect located on the substrate-film interface can cause RTFM in ZnO TFs. Interestingly, different substrates have been used to fabricate $\mathrm{ZnO}$ TFs with the same thickness by PED [94], and their ferromagnetic behaviors are very different. The ZnO TFs on silicon substrate show stronger ferromagnetism than the others, because more $V_{O}$ can be created in the TFs [94]. The origin of RTFM may be $V_{O}$.

ZnO TFs grown on sapphire substrates have been synthesized by PLD [105]. Only the samples on R-plane sapphire substrate exhibit RTFM. Furthermore, the results suggest that $\mathrm{V}_{\mathrm{Zn}}$ is probably the reason for the RTFM. In addition, quartz, glass, and silicon have been selected as substrates to prepare ZnO TFs by PLD, and the RTFM in the samples may come from the coupling of unpaired electron spins induced by the oxygen $2 p$ orbitals around the $\mathrm{V}_{\mathrm{Zn}}$ and are enhanced by the in-plane compressive strain [106].

The modulation of RTFM by changing the substrate temperature has also been studied in $\mathrm{ZnO}$ TFs [107]. However, $\mathrm{ZnO}$ films grown at low substrate temperatures exhibit a larger $M_{s} . M_{s}$ decreases with increasing the temperature. A similar result is found by $\mathrm{Xu}$ et al. [108]. Notably, the effect is different from that in TM-doped ZnO TFs [4]. 

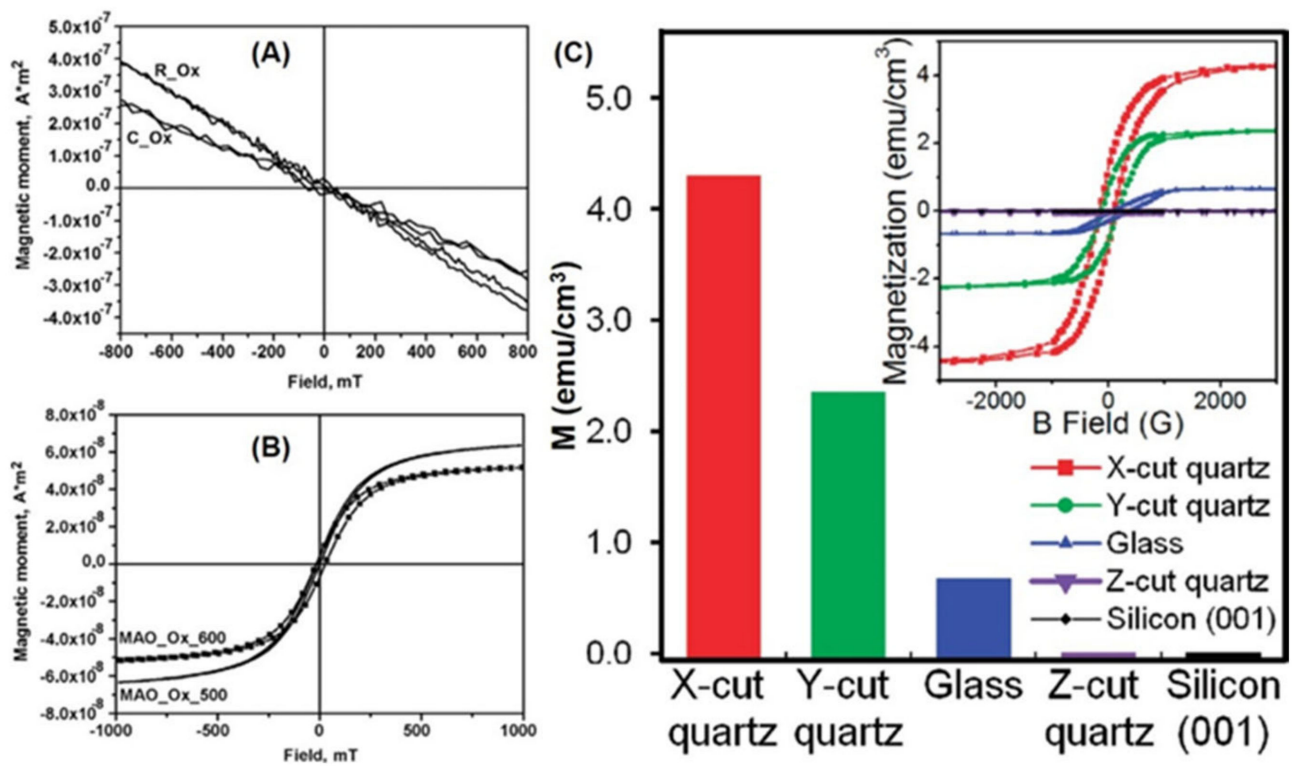

Figure 12. Substrate effects on RTFM. (A) M-H loops of ZnO TFs prepared by CVD on sapphire substrates (Reproduced with permission from [93]. Copyright 2019, Elsevier). (B) M-H loops of $\mathrm{ZnO}$ TFs deposited by CVD on (111) $\mathrm{MgAl}_{2} \mathrm{O}_{4}$ substrates (Reproduced with permission from [93]. Copyright 2019, Elsevier). (C) $M_{S}$ of ZnO TFs deposited on different substrates (Reproduced with permission from [106]. Copyright 2009, American Chemical Society).

\subsection{Effect of Growth Conditions on RTFM}

The RTFM can also be mediated by growth temperature. In 2012, Xu et al. [52] found that $\mathrm{ZnO}$ QDs with different sizes exhibited an obvious RTFM. Furthermore, the surface-volume ratio was closely related with the size-dependent ferromagnetism.

The size of QDs can also be controlled by milling time, which affects RTFM of QDs. Furthermore, it has been found that milling time is a superior way to mediate RTFM [49,57,58]. The grain size does not change monotonously with milling time, but $M_{S}$ will increase monotonously in a certain range. In fact, $\mathrm{V}_{\mathrm{Zn}}$ can induce RTFM in ZnO QDs.

Similarly, the grain size can be changed by milling time, as reported by Kisan et al. [57]. Interestingly, the transition from PM to FM is realized by this strategy. UV-vis spectra [57] and positron annihilation spectra [109] show that $V_{O}$ can affect the RTFM.

\subsection{Influence of Post-Annealing on RTFM}

Zhan et al. [110]. observed that RTFM can be produced by annealing in Ar. The magnetic field strength will affect the observed RTFM. When a magnetic field of 7T is applied, $M_{S}$ is as high as $2.7 \mathrm{emu} / \mathrm{g}$. Furthermore, PL spectra indicate that RTFM originates from $\mathrm{V}_{\mathrm{O}^{+}}$.

Undoped ZnO TFs with RTFM have been obtained by PAD [89]. The magnetization of the sample can potentiate by annealing in $\mathrm{O}_{2}$ or $\mathrm{H}_{2}$ gas. Positron annihilation spectroscopy indicates that $\mathrm{V}_{Z n}$ can induce the RTFM. In addition, we have also fabricated ferromagnetic $\mathrm{Zn}_{0.97} \mathrm{Co}_{0.03} \mathrm{O}$ TFs by PAD [90]. The $\mathrm{O}_{\mathrm{i}}$ and $\mathrm{V}_{\mathrm{Zn}}$ can be mediated with the annealing. The PL spectra show that the RTFM is closely related to $\mathrm{O}_{\mathrm{i}}$ and $\mathrm{V}_{\mathrm{Zn}}$.

Changing annealing temperature is another strategy to mediate RTFM [53,54] The $H_{c}$, $M_{r}$ and $M_{s}$ increase with decreasing the annealing temperature of the samples. PL spectra show that $Z n_{i}$ and $V_{O}$ related defects are closely related to the RTFM.

Interestingly, we have found that as-grown $\mathrm{ZnO}$ TFs can be transformed into centimeterscale $\mathrm{ZnO}$ horizontal NWs arrays [43] by annealing in $\mathrm{O}_{2}$. With the extension of annealing time, the length becomes longer. After $\mathrm{ZnO}$ NWs arrays have been produced, the magnetic properties of the films transform PM into FM. 


\subsection{Dopping with Non-Magnetic Atoms}

Notably, doping is also an effective way to modulate the RFTM of ZnO. Many research groups have attempted to look for compounds with RTFM since 2000, which can be obtained with doping transition metal elements into metal oxides such as $\mathrm{Cr}$ [4,111-113], Mn [2-4], Fe [114], Ni [115], Co [90,116-118], Sc [4,119,120], Ti [120], V [120], and Cu [120,121], and codoping such as CoFe [122], and MnCo [123]. However, experimental studies on TM-doped $\mathrm{ZnO}$ have produced inconsistent results and the mechanism of RTFM remains unclear. This promoted search for DMS based on alternative dopants. Manifestation of RTFM has also been undertaken by doping with non-magnetic dopants such as $\mathrm{H}[26,98-110,124,125], \mathrm{N}[126,127], \mathrm{C}[128-131]$, and S [47,78]. Interestingly, the observation of RTFM strongly suggests the presence of a spin-split band with a non-zero spin-orbit coupling in $\mathrm{H}-\mathrm{ZnO}$ single crystals [100]. In addition, incorporation of $\mathrm{N}$ at $60^{\circ}$ in $\mathrm{ZnO}$ induces the stronger FM, higher band gap reduction, larger reduction in surface roughness and higher reduction in the grains at RT [126]. Carbon-doped $\mathrm{ZnO}$ films show an intrinsic RTFM, which originates from the $\mathrm{Zn}-\mathrm{C}$ system in the $\mathrm{ZnO}$ environment [128]. Meanwhile, thiol-capped nanotube arrays have exhibited a higher $M_{s}$ than the nanowire arrays due to its larger surface-to-volume ratio and thus higher density of $\mathrm{Zn}-\mathrm{S}$ bond spins. The observed dependence of the magnetic anisotropy of $\mathrm{ZnO}$ NTs haves suggested that the change in the ordering of $\mathrm{Zn}-\mathrm{S}$ spins on the crystal facets can affect the extent of magnetic ordering and alter the preferred magnetization direction [78].

\subsection{Capping}

Capping organic molecules is a common method to mediate RTFM of non-magnetic materials. In 2007, Garcia et al. [36] controlled the ferromagnetism by capping ZnO NPs with three different organic molecules. The band structure was mediated with capping molecules, and then the RTFM was induced from DM.

\section{Conclusions and Outlook}

The present literature analysis reveals that the amount of research focused on undoped $\mathrm{ZnO}$ nanostructures with RFTM has been increasing over the past two decades. We have successfully prepared ferromagnetic nanostructures, including thin films, horizontal arrays and vertical arrays. RTFM could be readily modulated by non-doping means including precursor selection, substrate effects, growth conditions, post-annealing, and capping. Some novel ways to drive the transition from DM to FM in undoped $\mathrm{ZnO}$ nanostructures have delivered interesting results, as shown in Figure 12.

The size-dependent RTFM in ZnO QDs/NPs (Figure 3) can be observed [52]. $M_{s}$ is increased gradually by decreasing the diameters of $\mathrm{ZnO}$ QDs/NPs. However, in the nanowire system, the change of diameter has no obvious effect on RTFM (Figure 7). Interestingly, RTFM can be induced from non-magnetic $\mathrm{ZnO}$ nanosheets and TFs by reducing the thickness (Figures 10 and 12). Notably, the magnetic anisotropy of $\mathrm{ZnO}$ nanostructures should be further studied.

Through theoretical calculation, it has been found that there is a driving force of phase transformation in $\mathrm{ZnO}$. Therefore, fabrication of ultrathin (thickness $<2 \mathrm{~nm}$ ) freestanding $\mathrm{ZnO}$ structures remains challenging. Amazingly, Taniguchi et al. [45] have reported that organic layers could allow the formation of $\mathrm{ZnO}$ nanosheets $(\sim 1.5 \mathrm{~nm})$ with RTFM. In addition, Zhao et al. [132]. have presented the phase transitions of quantum-confined ZnO NWs by in-site TEM. Experimentally, it is still a great challenge to study RTFM in quantum-bound $\mathrm{ZnO}$ nanostructures.

Even though a variety of magnetic nanostructures have been prepared and studied, there are still many problems worthy of further study. (1) Development of new ferromagnetic nanostructures, such as nano-octagonal stars [133]. In the past, the morphology characterization mainly focused on 2D characterization. Recently, 3D electron tomography has emerged to analyze the 3D structure of nanostructures. In addition, the self-assembly of nanostructures and the evolution of ferromagnetism were further studied by an in 
situ method $[133,134]$. (2) Development of some emerging methods to prepare and study the nanostructure. (3) New characterization methods have been employed to investigate the nanostructures with RTFM $[135,136]$. The crystal nucleation process of FePt NPs in four dimensions [135] has been studied by atomic electron tomography (AET) [135]. In addition, electron tomography (ET) has revealed FeCo nano-octopods with RTFM. (4) The mechanism of undoped $\mathrm{ZnO}$ with RTFM needs further study.

Author Contributions: Writing-original draft preparation, H.R.; writing-review and editing, H.R. and G.X.; supervision, G.X. All authors have read and agreed to the published version of the manuscript.

Funding: This research was funded by the National Key R\&D Plan (Grant No. 2017YFB0405702), the National Natural Science Foundation of China (Grant No. 51671137), the Shandong Province Natural Science Foundation (Grant No. ZR2021MA042) and the Doctoral Scientific Research Foundation of Liaocheng University (Grant No. 318052054).

Institutional Review Board Statement: Not applicable.

Informed Consent Statement: Not applicable.

Data Availability Statement: Not applicable.

Conflicts of Interest: The authors declare no conflict of interest.

\section{References}

1. Wolf, S.A.; Awschalom, D.D.; Buhrman, R.A.; Daughton, J.M.; von Molnár, S.; Roukes, M.L.; Chtchelkanova, A.Y.; Treger, D.M. Spintronics: A Spin-Based Electronics Vision for the Future. Science 2001, 294, 1488-1495. [CrossRef]

2. Sharma, P.; Gupta, A.; Rao, K.V.; Owens, F.J.; Sharma, R.; Ahuja, R.; Osorio-Guillén, J.; Johansson, B.; Gehring, G.A. Ferromagnetism above room temperature in bulk and transparent thin films of Mn-doped ZnO. Nat. Mater. 2003, 2, 673-677. [CrossRef]

3. Kundaliya, D.C.; Ogale, S.B.; Lofland, S.; Dhar, S.; Metting, C.J.; Shinde, S.R.; Ma, Z.; Varughese, B.; Ramanujachary, K.; SalamancaRiba, L.; et al. On the origin of high-temperature ferromagnetism in the low-temperature-processed Mn-Zn-O system. Nat. Mater. 2004, 3, 709-714. [CrossRef]

4. Pan, F.; Song, C.; Liu, X.J.; Yang, Y.C.; Zeng, F. Ferromagnetism and possible application in spintronics of transition-metal-doped ZnO films. Mat. Sci. Eng. R. 2008, 62, 1-35. [CrossRef]

5. Herng, T.S.; Qi, D.; Berlijn, T.; Yi, J.; Yang, K.; Dai, Y.; Feng, Y.P.; Santoso, I.; Sánchez-Hanke, C.; Gao, X.Y.; et al. Room-Temperature Ferromagnetism of Cu-Doped ZnO Films Probed by Soft X-ray Magnetic Circular Dichroism. Phys. Rev. Lett. 2010, 105, 207201. [CrossRef] [PubMed]

6. Ning, S.; Zhan, P.; Xie, Q.; Wang, W.; Zhang, Z. Defects-Driven Ferromagnetism in Undoped Dilute Magnetic Oxides: A Review. J. Mater. Sci. Technol. 2015, 31,969-978. [CrossRef]

7. Hong, N.H.; Sakai, J.; Prellier, W.; Hassini, A.; Ruyter, A.; Gervais, F. Ferromagnetism in transition-metal-doped TiO 2 thin films. Phys. Rev. B. 2004, 70, 195204. [CrossRef]

8. Matsumoto, Y.; Murakami, M.; Shono, T.; Hasegawa, T.; Fukumura, T.; Kawasaki, M.; Ahmet, P.; Chikyow, T.; Koshihara, S.-Y.; Koinuma, H. Room-Temperature Ferromagnetism in Transparent Transition Metal-Doped Titanium Dioxide. Science 2001, 291, 854-856. [CrossRef] [PubMed]

9. Xu, X.H.; Blythe, H.J.; Ziese, M.; Behan, A.J.; Neal, J.R.; Mokhtari, A.; Ibrahim, R.M.; Fox, A.M.; Gehring, G.A. Carrier-induced ferromagnetism in n-type ZnMnAlO and ZnCoAlO thin films at room temperature. New J. Phys. 2006, 8, 135. [CrossRef]

10. Yoon, S.D.; Chen, Y.J.; Yang, A.; Goodrich, T.L.; Zuo, X.; Arena, D.A.; Ziemer, K.; Vittoria, C.; Harriset, V.G. Oxygen-defect-induced magnetism to $880 \mathrm{~K}$ in semiconducting anatase $\mathrm{TiO}_{2-\delta}$ films. J. Phys.-Condens. Mat. 2006, 18, 355-361. [CrossRef]

11. Ogale, S.B.; Choudhary, R.J.; Buban, J.P.; Lofland, S.E.; Shinde, S.R.; Kale, S.N.; Kulkarni, V.N.; Higgins, J.; Lanci, C.; Simpson, J.R.; et al. High temperature ferromagnetism with a giant magnetic moment in transparent Co-doped $\mathrm{SnO}_{2}$. Phys. Rev. Lett. 2003, 91, 077205. [CrossRef] [PubMed]

12. Coey, J.M.D.; Douvalis, A.P.; Fitzgerald, C.B.; Venkatesan, M. Ferromagnetism in Fe-doped $\mathrm{SnO}_{2}$ thin films. Appl. Phys. Lett. 2004, 84, 1332-1334. [CrossRef]

13. Gao, Y.; Hou, Q.Y.; Liu, Y. Effect of Fe Doping and Point Defects (VO and VSn) on the Magnetic Properties of SnO 2. J. Supercond. Nov. Magn. 2019, 32, 2877-2884. [CrossRef]

14. Lin, L.; Wang, P.; Huang, J.; Yu, W.; Tao, H.; Zhu, L.; Zhang, Z. Investigation on Electronic Structures and Magnetic Properties of (Mn, Ga) Co-doped $\mathrm{SnO}_{2}$. J. Supercond. Nov. Magn. 2019, 32, 3601-3607. [CrossRef]

15. Zhang, C.; Zhou, M.; Zhang, Y.; Hao, W.; Sun, L.; Cao, E.; Yang, Z. Effects of Oxygen Vacancy on the Magnetic Properties of Ni-Doped $\mathrm{SnO}_{2}$ Nanoparticles. J. Supercond. Nov. Magn. 2019, 32, 3509-3516. [CrossRef] 
16. Pereira, M.S.; Mendes, G.M.S.L.; Ribeiro, T.S.; Silva, M.R.; Vasconcelos, I.F. Influence of Thermal-Treatment Effects on the Structural and Magnetic Properties of $\mathrm{Sn} 1-\mathrm{xFexO} \mathrm{O}_{2}$ Nanopowders Produced by Mechanical Milling. J. Supercond. Nov. Magn . 2020, 33, 1721-1728. [CrossRef]

17. He, J.; Xu, S.F.; Yoo, Y.K.; Xue, Q.Z.; Lee, H.C.; Cheng, S.F.; Xiang, X.D.; Dionne, G.F.; Takeuchiet, I. Room temperature ferromagnetic n-type semiconductor in $\left(\mathrm{In}_{1-\mathrm{x}} \mathrm{Fe}_{\mathrm{x}}\right)_{2} \mathrm{O}_{3-\sigma}$. Appl. Phys. Lett. 2005, 86, 052503. [CrossRef]

18. Jiang, F.-X.; Xu, X.-H.; Zhang, J.; Fan, X.-C.; Wu, H.-S.; Gehring, G.A. Role of carrier and spin in tuning ferromagnetism in Mn and Cr-doped $\mathrm{In}_{2} \mathrm{O}_{3}$ thin films. Appl. Phys. Lett. 2010, 96, 52503. [CrossRef]

19. Venkatesan, M.; Fitzgerald, C.B.; Coey, J.M.D. Unexpected magnetism in a dielectric oxide. Nature 2004, 430, 630. [CrossRef]

20. Coey, J.M.D.; Venkatesan, M.; Stamenov, P.; Fitzgerald, C.B.; Dorneles, L.S. Magnetism in hafniumk dioxide. Phys. Rev. B 2005, 72, 024450. [CrossRef]

21. Hong, N.H.; Poirot, N.; Sakai, J. Evidence for magnetism due to oxygen vacancies in Fe-doped HfO 2 thin films. Appl. Phys. Lett. 2006, 89, 042503. [CrossRef]

22. Dietl, T.; Ohno, H.; Matsukura, F.; Cibert, J.; Ferrand, D. Zener model description of ferromagnetism in zinc-blende magnetic semico „,nductors. Science 2000, 287, 1019. [CrossRef]

23. Coey, J.M.D. $\mathrm{d}^{0}$ ferromagnetism. Solid State Sci. 2005, 7, 660-667. [CrossRef]

24. Avrutin, V.; Izyumskaya, N.; Üzgür, O.; Silversmith, D.J.; Morkoç, H. Ferromagnetism in ZnO- and GaN-based diluted magnetic Semiconductors: Achievements and challenges. Proc. IEEE 2010, 98, 1288-1301. [CrossRef]

25. Hernando, A.; Crespo, P.; Garcia, M.A.; Coey, J.M.D.; Ayuela, A.; Echenique, P.M. Revisiting magnetism of capped Au and ZnO nanoparticles: Surface band structure and atomic orbital with giant magnetic moment. Phys. Status Solidi B 2011, 248, 2352-2360. [CrossRef]

26. Esquinazi, P.; Hergert, W.; Spemann, D.; Setzer, A.; Ernst, A. Defect-Induced Magnetism in Solids. IEEE Trans. Magn. 2013, 49, 4668-4674. [CrossRef]

27. Singh, R. Unexpected magnetism in nanomaterials. J. Magn. Magn. Mater. 2013, 346, 58-73. [CrossRef]

28. Opel, M.; Goennenwein, S.T.B.; Althammer, M.; Nielsen, K.-W.; Karrer-Müller, E.-M.; Bauer, S.; Senn, K.; Schwark, C.; Weier, C.; Güntherodt, G.; et al. Zinc oxide -From dilute magnetic doping to spin transport. Phys. Status Solidi B 2014, 251, 1700-1709. [CrossRef]

29. Zhang, J.; Yu, L.; Song, Q.; Du, Y. Tunable surface and/or interface ferromagnetism of ZnO nanoparticles. Ann. Phys. 2015, 358, 159-171. [CrossRef]

30. Semisalova, A.S.; Orlov, A.; Smekhova, A.; Gan'shina, E.; Perov, N.; Anwand, W.; Potzger, K.; Lähderanta, E.; Granovsky, A. Above room temperature ferromagnetism in dilute magnetic oxide semiconductors. In Novel Functional Magnetic Materials: Fundamentals and Applications; Zhukov, A., Ed.; Springer International Publishing: Cham, Switzerland, 2016; pp. 187-219.

31. Qi, B.; Ólafsson, S.; Gíslason, H. Vacancy defect-induced d0 ferromagnetism in undoped ZnO nanostructures: Controversial origin and challenges. Prog. Mater. Sci. 2017, 90, 45-74. [CrossRef]

32. Aravind, A.; Jayaraj, M.K. ZnO-based dilute magnetic semiconductors. In Nanostructured Metal Oxides and Devices: Optical and Electrical Properties; Jayaraj, M.K., Ed.; Springer: Singapore, 2020; pp. 233-269.

33. Li, X.-L.; Xu, X.-H. Homogeneous and inhomogeneous magnetic oxide semiconductors. Chin. Phys. B 2019, 28, 098506. [CrossRef]

34. Galland, D.; Herve, A. ESR spectra of the zinc vacancy in ZnO. Phys. Lett. A 1970, 33, 1-2. [CrossRef]

35. Potzger, K.; Zhou, S.Q.; Grenzer, J.; Helm, M.; Fassbender, J. An easy mechanical way to create ferromagnetic defective ZnO. Appl. Phys. Lett. 2008, 92, 182504. [CrossRef]

36. Garcia, M.A.; Merino, J.M.; Fernández, P.E.; Quesada, A.; De la Venta, J.; Ruíz, G.M.L.; Hernando, A. Magnetic properties of ZnO nanoparticles. Nano Lett. 2007, 7, 1489-1494. [CrossRef] [PubMed]

37. Köseoğlu, Y. A simple microwave-assisted combustion synthesis and structural, optical and magnetic characterization of $\mathrm{ZnO}$ nanoplatelets. Ceram. Int. 2014, 40, 4673-4679. [CrossRef]

38. Sundaresan, A.; Bhargavi, R.; Rangarajan, N.; Siddesh, U.; Rao, C.N.R. Ferromagnetism as a universal feature of nanoparticles of the otherwise nonmagnetic oxides. Phys. Rev. B 2006, 74, 161306. [CrossRef]

39. Banerjee, S.; Mandal, M.; Gayathri, N.; Sardar, M. Enhancement of ferromagnetism upon thermal annealing in pure ZnO. Appl. Phys. Lett. 2007, 91, 182501. [CrossRef]

40. Hong, N.H.; Sakai, J.; Brizé, V. Observation of ferromagnetism at room temperature in ZnO thin films. J. Phy. Condens. Matter 2007, 19. [CrossRef]

41. Yin, X.; Wang, Y.Z.; Jacobs, R.; Shi, Y.Q.; Szlufarska, I.; Morgan, D.; Wang, X.D. Massive vacancy concentration yields strong room-temperature ferromagnetism in two-dimensional ZnO. Nano Lett. 2019, 19, 7085-7092. [CrossRef]

42. Ren, H.; Liu, Y.; Zhang, L.; Liu, K. Synthesis, properties, and applications of large-scale two-dimensional materials by polymerassisted deposition. J. Semicond. 2019, 40. [CrossRef]

43. Ren, H.; Xiang, G.; Luo, J.; Yang, D.; Zhang, X. Direct catalyst-free self-assembly of large area of horizontal ferromagnetic ZnO nanowire arrays. Mater. Lett. 2018, 234, 384-387. [CrossRef]

44. Luo, J.; Ren, H.; Zhang, X.; Xiang, G. Fabrication of vertically aligned ferromagnetic ZnO nanopillar arrays on sapphire substrates by polymer-assisted deposition. AIP Adv. 2020, 10, 015337. [CrossRef] 
45. Taniguchi, T.; Yamaguchi, K.; Shigeta, A.; Matsuda, Y.; Hayami, S.; Shimizu, T.; Matsui, T.; Yamazaki, T.; Funatstu, A.; Makinose, Y.; et al. Enhanced and Engineered d0Ferromagnetism in Molecularly-Thin Zinc Oxide Nanosheets. Adv. Funct. Mater. 2013, 23, 3140-3145. [CrossRef]

46. Xu, Q.; Zhou, S.; Schmidt, H. Magnetic properties of ZnO nanopowders. J. Alloys Compd. 2009, 487, 665-667. [CrossRef]

47. Chaboy, J.; Boada, R.; Piquer, C.; Marco, M.A.L.; García-Hernández, M.; Carmona, N.; Llopis, J.; Gonzalez, M.L.R.; Gonzalez-Calbet, J.M.; Fernandez, J.; et al. Evidence of intrinsic magnetism in capped ZnO nanoparticles. Phys. Rev. B 2010, 82. [CrossRef]

48. Xu, Q.; Wen, Z.; Zhang, H.; Qi, X.; Zhong, W.; Xu, L.; Wu, D.; Shen, K.; Xu, M. Room temperature ferromagnetism in ZnO prepared by microemulsion. AIP Adv. 2011, 1, 032127. [CrossRef]

49. Phan, T.-L.; Zhang, Y.D.; Yang, D.S.; Nghia, N.X.; Thanh, T.D.; Yu, S.C. Defect-induced ferromagnetism in ZnO nanoparticles prepared by mechanical milling. Appl. Phys. Lett. 2013, 102, 072408. [CrossRef]

50. Lemine, O.M. Induced Room-Temperature Ferromagnetism in Un-doped Nanocrystalline Metal Oxide Powders Obtained by Mechanical Milling: A Review. J. Supercond. Nov. Magn. 2016, 30, 271-274. [CrossRef]

51. Zhao, C.; Huang, Y.; Abiade, J.T. Ferromagnetic ZnO nanoparticles prepared by pulsed laser deposition in liquid. Mater. Lett. 2012, 85, 164-167. [CrossRef]

52. Xu, X.; Xu, C.; Dai, J.; Hu, J.; Li, F.; Zhang, S. Size Dependence of Defect-Induced Room Temperature Ferromagnetism in Undoped ZnO Nanoparticles. J. Phys. Chem. C 2012, 116, 8813-8818. [CrossRef]

53. Zhang, Y.; Xie, E. Nature of room-temperature ferromagnetism from undoped ZnO nanoparticles. Appl. Phys. A 2010, 99, 955-960. [CrossRef]

54. Naji Aljawfi, R.; Rahman, F.; Shukla, D.K. Effect of the annealing temperature on the structural and magnetic properties of ZnO nanoparticles. Mater. Lett. 2013, 99, 18-20. [CrossRef]

55. Ghose, S.; Gogurla, N.; Ranganathan, R.; Jana, D. The simultaneous emergence of free exciton emission and d0 ferromagnetism for undoped ZnO nanoparticles. RSC Adv. 2016, 6, 83909-83915. [CrossRef]

56. Ghose, S.; Rakshit, T.; Ranganathan, R.; Jana, D. Role of Zn-interstitial defect states on d0 ferromagnetism of mechanically milled ZnO nanoparticles. RSC Adv. 2015, 5, 99766-99774. [CrossRef]

57. Kisan, B.; Alagarsamy, P. Room temperature ferromagnetism in finite sized ZnO nanoparticles. Phys. B Condens. Matter 2014, 448, 115-119. [CrossRef]

58. Kisan, B.; Kumar, J.; Alagarsamy, P. Experimental and first-principles study of defect-induced electronic and magnetic properties of ZnO nanocrystals. J. Phys. Chem. Solids 2020, 146, 109580. [CrossRef]

59. Wang, D.; Chen, Z.Q.; Wang, D.D.; Qi, N.; Gong, J.; Cao, C.Y.; Tang, Z. Positron annihilation study of the interfacial defects in ZnO nanocrystals: Correlation with ferromagnetism. J. Appl. Phys. 2010, 107, 023524. [CrossRef]

60. Ghose, S.; Sarkar, A.; Chattopadhyay, S.; Chakrabarti, M.; Das, D.; Rakshit, T.; Ray, S.K.; Jana, D. Surface defects induced ferromagnetism in mechanically milled nanocrystalline ZnO. J. Appl. Phys. 2013, 114, 073516. [CrossRef]

61. Xue, X.; Liu, L.; Wang, Z.; Wu, Y. Room-temperature ferromagnetism in hydrogenated ZnO nanoparticles. J. Appl. Phys. 2014, 115, 33902. [CrossRef]

62. Gao, D.; Zhang, Z.; Fu, J.; Xu, Y.; Qi, J.; Xue, D. Room temperature ferromagnetism of pure ZnO nanoparticles. J. Appl. Phys. 2009, 105, 113928. [CrossRef]

63. Pazhanivelu, V.; Blessington Selvadurai, A.P.; Murugaraj, R. Unexpected ferromagnetism in Ist group elements doped ZnO based DMS nanoparticles. Mater. Lett. 2015, 151, 112-114. [CrossRef]

64. Wangensteen, T.; Dhakal, T.; Merlak, M.; Mukherjee, P.; Phan, M.; Chandra, S.; Srikanth, H.; Witanachchi, S. Growth of uniform ZnO nanoparticles by a microwave plasma process. J. Alloys Compd. 2011, 509, 6859-6863. [CrossRef]

65. Yan, Z.; Ma, Y.; Wang, D.; Wang, J.; Gao, Z.; Song, T. Surfactant-Free Fabrication of ZnO Spheres and Pseudospherical Structures. J. Phys. Chem. C 2008, 112, 9219-9222. [CrossRef]

66. Yi, J.B.; Pan, H.; Lin, J.Y.; Ding, J.; Feng, Y.P.; Thongmee, S.; Liu, T.; Gong, H.; Wang, L. Ferromagnetism in ZnO Nanowires Derived from Electro-deposition on AAO Template and Subsequent Oxidation. Adv. Mater. 2008, 20, 1170-1174. [CrossRef]

67. Yan, Z.; Ma, Y.; Wang, D.; Wang, J.; Gao, Z.; Wang, L.; Yu, P.; Song, T. Impact of annealing on morphology and ferromagnetism of ZnO nanorods. Appl. Phys. Lett. 2008, 92, 081911. [CrossRef]

68. Kumar, S.; Kim, Y.; Koo, B.; Gautam, S.; Chae, K.H.; Kumar, R.; Lee, C. Room temperature ferromagnetism in chemically synthesized ZnO rods. Mater. Lett. 2009, 63, 194-196. [CrossRef]

69. Podila, R.; Queen, W.; Nath, A.; Arantes, J.T.; Schoenhalz, A.L.; Fazzio, A.; Dalpian, G.M.; He, J.; Hwu, S.J.; Skove, M.J.; et al. Origin of FM Ordering in Pristine Micro- and Nanostructured ZnO. Nano Lett. 2010, 10, 1383-1386. [CrossRef]

70. Panigrahy, B.; Aslam, M.; Misra, D.S.; Ghosh, M.; Bahadur, D. Defect-Related Emissions and Magnetization Properties of ZnO Nanorods. Adv. Funct. Mater. 2010, 20, 1161-1165. [CrossRef]

71. Xing, G.Z.; Wang, D.D.; Yi, J.B.; Yang, L.L.; Gao, M.; He, M.; Yang, J.H.; Ding, J.; Sum, T.C.; Wu, T. Correlated d ${ }^{0}$ ferromagnetism and photoluminescence in undoped ZnO nanowires. Appl. Phys. Lett. 2010, 96, 112511. [CrossRef]

72. Jana, A.; Sujatha Devi, P.; Mitra, A.; Bandyopadhyay, N.R. Synthesis of blue emitting ZnO nanorods exhibiting room temperature ferromagnetism. Mater. Chem. Phys. 2013, 139, 431-436. [CrossRef]

73. Ghosh, B.; Ray, S.C.; Pontsho, M.; Sarma, S.; Mishra, D.K.; Wang, Y.F.; Pong, W.F.; Strydom, A.M. Defect induced room temperature ferromagnetism in single crystal, poly-crystal, and nanorod ZnO: A comparative study. J. Appl. Phys. 2018, 123, 161507. [CrossRef] 
74. Xu, X.Y.; Xu, C.X.; Lin, Y.; Ding, T.; Fang, S.J.; Shi, Z.L.; Xia, W.W.; Hu, J.G. Surface photoluminescence and magnetism in hydrothermally grown undoped $\mathrm{ZnO}$ nanorod arrays. Appl. Phys. Lett. 2012, 100, 172401. [CrossRef]

75. Li, Z.; Zhong, W.; Li, X.; Zeng, H.; Wang, G.; Wang, W.; Yang, Z.; Zhang, Y. Strong room-temperature ferromagnetism of pure $\mathrm{ZnO}$ nanostructure arrays via colloidal template. J. Mater. Chem. C 2013, 1, 6807-6812. [CrossRef]

76. Xu, X.; Xu, C.; Lin, Y.; Li, J.; Hu, J. Comparison on Photoluminescence and Magnetism between Two Kinds of Undoped ZnO Nanorods. J. Phys. Chem. C 2013, 117, 24549-24553. [CrossRef]

77. Singh, S.B.; Wang, Y.-F.; Shao, Y.-C.; Lai, H.-Y.; Hsieh, S.-H.; Limaye, M.V.; Chuang, C.-H.; Hsueh, H.-C.; Wang, H.; Chiou, J.-W.; et al. Observation of the origin of d0magnetism in $\mathrm{ZnO}$ nanostructures using X-ray-based microscopic and spectroscopic techniques. Nanoscale 2014, 6, 9166-9176. [CrossRef]

78. Deng, S.Z.; Fan, H.M.; Wang, M.; Zheng, M.R.; Yi, J.B.; Wu, R.Q.; Tan, H.R.; Sow, C.H.; Ding, J.; Loh, Y.P.K.P. Thiol-capped ZnO nanowire/nanotube arrays with tunable magnetic properties at toom temperature. ACS Nano 2010, 4, 495-505. [CrossRef]

79. Bie, X.; Wang, C.; Ehrenberg, H.; Wei, Y.; Chen, G.; Meng, X.; Zou, G.; Du, F. Room-temperature ferromagnetism in pure ZnO nanoflowers. Solid State Sci. 2010, 12, 1364-1367. [CrossRef]

80. Gupta, J.; Bhargava, P.; Bahadur, D. Morphology dependent photocatalytic and magnetic properties of ZnO nanostructures. Phys. $B$ Condens. Matter 2014, 448, 16-19. [CrossRef]

81. Motaung, D.E.; Mhlongo, G.H.; Nkosi, S.S.; Malgas, G.F.; Mwakikunga, B.W.; Coetsee, E.; Swart, H.C.; Abdallah, H.M.I.; Moyo, T.; Ray, S.S. Shape-Selective Dependence of Room Temperature Ferromagnetism Induced by Hierarchical ZnO Nanostructures. ACS Appl. Mater. Interfaces 2014, 6, 8981-8995. [CrossRef] [PubMed]

82. Hong, J.-I.; Choi, J.; Jang, S.S.; Gu, J.; Chang, Y.; Wortman, G.; Snyder, R.L.; Wang, Z.L. Magnetism in Dopant-Free ZnO Nanoplates. Nano Lett. 2012, 12, 576-581. [CrossRef]

83. Yang, H.-F.; Tang, L.-Z.; Sun, Q.; Sun, L.; Li, Z.-H.; Ren, S.-X. Ferromagnetism in High-Surface-Area ZnO Nanosheets Prepared by a Template-Assisted Hydrothermal Method. Chin. Phys. Lett. 2018, 35. [CrossRef]

84. Wang, Q.; Sun, Q.; Chen, G.; Kawazoe, Y.; Jena, P. Vacancy-induced magnetism in ZnO thin films and nanowires. Phys. Rev. B 2008, 77, 205411. [CrossRef]

85. Kapilashrami, M.; Xu, J.; Ström, V.; Rao, K.V.; Belova, L. Transition from ferromagnetism to diamagnetism in undoped ZnO thin films. Appl. Phys. Lett. 2009, 95, 033104. [CrossRef]

86. Straumal, B.; Mazilkin, A.; Protasova, S.; Myatiev, A.; Goering, E.; Baretzky, B. Amorphous grain boundary layers in the ferromagnetic nanograined ZnO films. Thin Solid Films 2011, 520, 1192-1194. [CrossRef]

87. Tietze, T.; Audehm, P.; Chen, Y.C.; Schütz, G.; Straumal, B.B.; Protasova, S.G.; Mazilkin, A.A.; Straumal, P.B.; Prokscha, T.; Luetkens, H.; et al. Interfacial dominated ferromagnetism in nanograined ZnO: A $\mu$ SR and DFT study. Sci. Rep. 2015, 5, 8871. [CrossRef] [PubMed]

88. Xing, G.Z.; Lu, Y.H.; Tian, Y.F.; Yi, J.B.; Lim, C.C.; Li, Y.F.; Li, G.P.; Wang, D.D.; Yao, B.; Ding, J.; et al. Defect-induced magnetism in undoped wide band gap oxides: Zinc vacancies in $\mathrm{ZnO}$ as an example. AIP Adv. 2011, 1, 022152. [CrossRef]

89. Ren, H.T.; Xiang, G.; Gu, G.; Wang, W.J.; Zhang, P.; Wang, B.Y.; Cao, X.Z. Zinc Vacancy-induced room-temperature ferromagnetism in undoped $\mathrm{ZnO}$ thin films. J. Nanomat. 2012, 2012, 295358. [CrossRef]

90. Ren, H.T.; Xiang, G.; Gu, G.X.; Zhang, X. Enhancement of ferromagnetism of ZnO:Co nanocrystals by post-annealing treatment: The role of oxygen interstitials and zinc vacancies. Mater. Lett. 2014, 122, 256-260. [CrossRef]

91. Mal, S.; Narayan, J.; Nori, S.; Prater, J.; Kumar, D. Defect-mediated room temperature ferromagnetism in zinc oxide. Solid State Commun. 2010, 150, 1660-1664. [CrossRef]

92. Kapilashrami, M.; Xu, J.; Biswas, A.; Tamaki, T.; Sharma, P.; Rao, K.; Belova, L. Coexistence of ultraviolet photo-response and room-temperature ferromagnetism in polycrystalline ZnO thin films. Mater. Lett. 2010, 64, 1291-1294. [CrossRef]

93. Burova, L.I.; Perov, N.S.; Semisalova, A.S.; Kulbachinskii, V.A.; Vladimir, G.; Kytin, V.G.; Roddatis, V.V.; Alexander, L.; Vasiliev, A.L.; Andrey, R.; et al. Effect of the nanostructure on room temperature ferromagnetism and resistivity of undoped ZnO thin films grown by chemical vapor deposition. Thin Solid Films 2012, 520, 4580-4585. [CrossRef]

94. Zhan, P.; Wang, W.; Xie, Z.; Li, Z.; Zhang, Z.; Zhang, P.; Wang, B.; Cao, X. Substrate effect on the room-temperature ferromagnetism in un-doped ZnO films. Appl. Phys. Lett. 2012, 101, 031913. [CrossRef]

95. Zhao, J.G.; Zhang, W.Y.; An, X.Y.; Liu, Z.J.; Xie, E.Q.; Yang, C.; Chen, L.L. Room-temperature ferromagnetism in ZnO nanoparticles by electrospinning. Nanosci. Nanotech. Lett. 2014, 6, 446-449. [CrossRef]

96. Zhang, X.; Zhang, W.; Zhang, X.; Xu, X.; Meng, F.; Tang, C.C. Defects Induced Room Temperature Ferromagnetism in ZnO Thin Films. Adv. Condens. Matter Phys. 2014, 2014, 806327. [CrossRef]

97. Mishra, D.; Kumar, P.; Sharma, M.K.; Das, J.; Singh, S.; Roul, B.; Varma, S.; Chatterjee, R.; Srinivasu, V.; Kanjilal, D. Ferromagnetism in ZnO single crystal. Phys. B Condens. Matter 2010, 405, 2659-2663. [CrossRef]

98. Sanchez, N.; Gallego, S.; Cerdá, J.; Muñoz, M.C. Tuning surface metallicity and ferromagnetism by hydrogen adsorption at the polar $\mathrm{ZnO}(0001)$ surface. Phys. Rev. B 2010, 81. [CrossRef]

99. Khalid, M.; Esquinazi, P.; Spemann, D.; Anwand, W.; Bräuer, G. Hydrogen-mediated ferromagnetism in ZnO single crystals. New J. Phys. 2011, 13, 063017. [CrossRef]

100. Khalid, M.; Esquinazi, P.D. Hydrogen-induced ferromagnetism in ZnO single crystals investigated by magnetotransport. Phys. Rev. B 2012, 85. [CrossRef] 
101. Khazanov, E.N.; Taranov, A.V.; Salamatov, E.I.; Shevchenko, E.V.; Charnaya, E.V. Features of defects of the crystal structure and magnetic properties of an undoped ZnO monocrystal. J. Commun. Technol. Electron. 2017, 62, 406-409. [CrossRef]

102. Xia, Z.B.; Sha, J.; Fang, Y.J.; Wan, Y.T.; Wang, Z.L.; Wang, Y.W. Purposed built $\mathrm{ZnO} / \mathrm{Zn}_{5}(\mathrm{OH})_{8} \mathrm{Ac}_{2} \cdot 2 \mathrm{H}_{2} \mathrm{O}$ architectures by hydrothermal synthesis. Cryst. Growth Des. 2010, 10, 2759-2765. [CrossRef]

103. Xia, Z.B.; Wang, Y.W.; Fang, Y.J.; Wan, Y.T.; Xia, W.; Sha, J. Understanding the origin of ferromagnetism in ZnO porous microspheres by systematic investigations of the thermal decomposition of $\mathrm{Zn}_{5}(\mathrm{OH})_{8} \mathrm{Ac}_{2} \cdot 2 \mathrm{H}_{2} \mathrm{O}$ to $\mathrm{ZnO}$. J. Phys. Chem. C 2011, 115, 14576-14582. [CrossRef]

104. Tóthová, E.; Senna, M.; Yermakov, A.; Kováč, J.; Dutková, E.; Hegedüs, M.; Kaňuchová, M.; Baláž, M.; Bujňáková, Z.L.; Briančin, J.; et al. Zn source-dependent magnetic properties of undoped $\mathrm{ZnO}$ nanoparticles from mechanochemically derived hydrozincite. J. Alloys Compd. 2019, 787, 1249-1259. [CrossRef]

105. Khalid, M.; Ziese, M.; Setzer, A.P.; Esquinazi, P.M.; Lorenz, M.H.; Hochmuth, H.; Grundmann, M.; Spemann, D.; Butz, T.; Brauer, G.; et al. Defect-induced magnetic order in pure ZnO films. Phys. Rev. B 2009, 80, 035331. [CrossRef]

106. Ong, C.S.; Herng, T.S.; Huang, X.L.; Feng, Y.P.; Ding, J. Strain-Induced ZnO Spinterfaces. J. Phys. Chem. C 2011, 116, 610-617. [CrossRef]

107. Mal, S.; Nori, S.; Narayan, J.; Prater, J.T. Defect-mediated ferromagnetism and controlled switching characteristics in ZnO. J. Mater. Res. 2011, 26, 1298-1308. [CrossRef]

108. Xu, Q.; Wen, Z.; Xu, L.; Gao, J.; Wu, D.; Shen, K.; Qiu, T.; Tang, S.; Xu, M. Room temperature ferromagnetic pure ZnO. Phys. B Condens. Matter 2011, 406, 19-23. [CrossRef]

109. Sanyal, D.; Chakrabarti, M.; Roy, T.K.; Chakrabarti, A. The origin of ferromagnetism and defect-magnetization correlation in nanocrystalline ZnO. Phys. Lett. A 2007, 371, 482-485. [CrossRef]

110. Zhan, P.; Wang, W.; Xie, Q.; Li, Z.; Zhang, Z. Enhanced room-temperature ferromagnetism in un-doped ZnO thin films by thermal annealing in a strong magnetic field. J. Appl. Phys. 2012, 111, 103524. [CrossRef]

111. Hong, N.H.; Sakai, J.; Huong, N.T.; Poirot, N.; Ruyter, A. Role of defects in tuning ferromagnetism in diluted magnetic oxide thin films. Phys. Rev. B 2005, 72, 045336. [CrossRef]

112. Liu, H.; Zhang, X.; Li, L.; Wang, Y.X.; Gao, K.H.; Li, Z.Q.; Zheng, R.; Ringer, S.; Zhang, B. Role of point defects in room-temperature ferromagnetism of Cr-doped ZnO. Appl. Phys. Lett. 2007, 91, 72511. [CrossRef]

113. Wang, Q.; Sun, Q.; Jena, P.; Kawazoe, Y. Magnetic coupling between Cr atoms doped at bulk and surface sites of ZnO. Appl. Phys. Lett. 2005, 87, 162509. [CrossRef]

114. Thurber, A.P.; Beausoleil II, G.L.; Alanko, G.A.; Anghel, J.J.; Jones, M.S.; Johnson, L.M.; Zhang, J.H.; Hanna, C.B.; Tenne, D.A.; Punnoose, A. Magnetism of $\mathrm{ZnO}$ nanoparticles: Dependence on crystallite size and surfactant coating. J. Appl. Phys. 2011, 109, 07C305. [CrossRef]

115. Rana, A.K.; Kumar, Y.; Rajput, P.; Jha, S.N.; Bhattacharyya, D.; Shirage, P.M. Search for origin of room temperature ferromagnetism properties in Ni-doped ZnO nanostructure. ACS Appl. Mater. Inter. 2017, 9, 7691-7700. [CrossRef]

116. Wojnarowicz, J.; Kusnieruk, S.; Chudoba, T.; Gierlotka, S.; Lojkowski, W.; Knoff, W.; Lukasiewicz, M.I.; Witkowski, B.; Wolska, A.; Klepka, M.; et al. Paramagnetism of cobalt-doped ZnO nanoparticles obtained by microwave solvothermal synthesis. Beilstein J. Nanotechnol. 2015, 6, 1957-1969. [CrossRef] [PubMed]

117. MacManus-Driscoll, J.L.; Khare, N.; Liu, Y.; Vickers, M.E. Structural Evidence for Zn Intersititials in Ferromagnetic Zn1-xCoxO Films. Adv. Mater. 2007, 19, 2925-2929. [CrossRef]

118. Chen, R.; Luo, F.C.; Liu, Y.Z.; Song, Y.; Dong, Y.; Wu, S.; Cao, J.H.; Yang, F.Y.; N’Diaye, A.; Shafer, P.; et al. Tunable roomtemperature ferromagnetism in Co-doped two-dimensional van der Waals ZnO. Nat. Commun. 2021, 12, 3953. [CrossRef]

119. Coey, J.; Venkatesan, M.; Fitzgerald, C.; Dorneles, L.; Stamenov, P.; Lunney, J. Anisotropy of the magnetization of a dilute magnetic oxide. J. Magn. Magn. Mater. 2004, 290-291, 1405-1407. [CrossRef]

120. Venkatesan, M.; Fitzgerald, C.B.; Lunney, J.G.; Coey, J.M.D. Anisotropic Ferromagnetism in Substituted Zinc Oxide. Phys. Rev. Lett. 2004, 93, 177206. [CrossRef] [PubMed]

121. Buchholz, D.B.; Chang, R.P.H.; Song, J.H.; Ketterson, J.B. Room-temperature Ferromagnetism in Cu-doped ZnO Thin Films. Appl. Phys. Lett. 2005, 87, 082504. [CrossRef]

122. Huang, J.C.A.; Hsu, H.S. Inspection of magnetic semiconductor and clustering structure in CoFe-doped $\mathrm{ZnO}$ films by biasdependent impedance spectroscopy. Appl. Phys. Lett. 2005, 87, 132503. [CrossRef]

123. Du, C.L.; Gu, Z.B.; Lu, M.H.; Wang, J.; Zhang, S.T.; Zhao, J.; Cheng, G.X.; Heng, H.; Chen, Y.F. Raman spectroscopy of (Mn, Co)-codoped ZnO films. J. Appl. Phys. 2006, 99, 123515. [CrossRef]

124. Robaina, O.V.; Cabrera, A.F.; Meyer, M.; Romano, R.M.; Cruz, A.F.; Torres, C.E.R. Room-Temperature Ferromagnetism Induced by High-Pressure Hydrogenation of ZnO. J. Phys. Chem. C 2019, 123, 19851-19861. [CrossRef]

125. Salimian, A.; Abul, H.A.; Aminishahsavarani, A.; Upadhyaya, H. Hypothesis on the influence of the magnetic behaviour of hydrogen doped Zinc oxide during its plasma sputtering process. Coatings 2021, 11, 222. [CrossRef]

126. Hariwal, R.V.; Malik, H.K.; Negi, A.; Kandasami, A. Controlling room temperature ferromagnetism and band gap in ZnO nanostructured thin films by varying angle of implantation. RSC Adv. 2018, 8, 6278-6287. [CrossRef]

127. Jindal, K.; Tomar, M.; Katiyar, R.; Gupta, V. Transition from diamagnetic to ferromagnetic state in laser ablated nitrogen doped ZnO thin films. AIP Adv. 2015, 5, 027117. [CrossRef] 
128. Pan, H.; Yi, J.B.; Shen, L.; Wu, R.Q.; Yang, J.H.; Lin, J.Y.; Feng, Y.P.; Ding, J.; Van, L.H.; Yin, J.H. Room-temperature ferromagnetism in Carbon-doped ZnO. Phys. Rev. Lett. 2007, 99, 127201. [CrossRef]

129. Nagare, B.J.; Chacko, S.; Kanhere, D.G. Ferromagnetism in Carbon-Doped Zinc Oxide Systems. J. Phys. Chem. A 2010, 114, 2689-2696. [CrossRef]

130. Pham, A.; Assadi, M.H.N.; Zhang, Y.B.; Yu, A.B.; Li, S. Weak $\mathrm{d}^{0}$ magnetism in C and N doped ZnO. J. Appl. Phys. 2011, $110,123917$. [CrossRef]

131. Kumar, P.; Malik, H.K.; Asokan, K.; Kandasami, A. Tuning of optical bandgap and magnetization of C-implanted ZnO thin films. EPL Europhys. Lett. 2015, 110, 67006. [CrossRef]

132. Zhao, P.; Guan, X.; Zheng, H.; Jia, S.; Li, L.; Liu, H.; Zhao, L.; Sheng, H.; Meng, W.; Zhuang, Y.; et al. Surface- and Strain-Mediated Reversible Phase Transformation in Quantum-Confined ZnO Nanowires. Phys. Rev. Lett. 2019, 123, 216101. [CrossRef]

133. Garnero, C.; Pierrot, A.; Gatel, C.; Marcelot, C.; Arenal, R.; Florea, I.; Mantel, A.B.; Soulantica, K.; Poveda, P.; Chaudret, B.; et al. Single-crystalline body centered FeCo nano-octopods: From one-pot chemical growth to a complex 3D magnetic configuration. Nano Lett. 2021, 21, 3664-3670. [CrossRef] [PubMed]

134. Ye, S.; Chen, Z.; Ha, Y.-C.; Wiley, B.J. Real-Time Visualization of Diffusion-Controlled Nanowire Growth in Solution. Nano Lett. 2014, 14, 4671-4676. [CrossRef]

135. Zhou, J.H.; Yang, Y.S.; Yang, Y.; Kim, D.S.; Yuan, A.; Tian, X.Z.; Ophus, C.; Sun, F.; Schmid, A.K.; Nathanson, M.; et al. Observing crystal nucleation in four dimensions using atomic electron tomography. Nature 2019, 570, 500-503. [CrossRef] [PubMed]

136. Schreiber, R.E.; Houben, L.; Wolf, S.G.; Leitus, G.; Lang, Z.-L.; Carbó, J.J.; Poblet, Z.-L.L.J.J.C.J.M.; Neumann, R.E.S.R. Real-time molecular scale observation of crystal formation. Nat. Chem. 2016, 9, 369-373. [CrossRef] [PubMed] 